\title{
Immersive GeoDesign: Exploring the Built Environment through the Coupling of GeoDesign, 3D Modeling, and Immersive Geography
}

Marvin Davis

Follow this and additional works at: https://researchrepository.wvu.edu/etd

\section{Recommended Citation}

Davis, Marvin, "Immersive GeoDesign: Exploring the Built Environment through the Coupling of GeoDesign, 3D Modeling, and Immersive Geography" (2016). Graduate Theses, Dissertations, and Problem Reports. 5445.

https://researchrepository.wvu.edu/etd/5445

This Thesis is protected by copyright and/or related rights. It has been brought to you by the The Research Repository @ WVU with permission from the rights-holder(s). You are free to use this Thesis in any way that is permitted by the copyright and related rights legislation that applies to your use. For other uses you must obtain permission from the rights-holder(s) directly, unless additional rights are indicated by a Creative Commons license in the record and/ or on the work itself. This Thesis has been accepted for inclusion in WVU Graduate Theses, Dissertations, and Problem Reports collection by an authorized administrator of The Research Repository @ WVU. For more information, please contact researchrepository@mail.wvu.edu. 


\title{
Immersive GeoDesign: Exploring the Built Environment through the Coupling of GeoDesign, 3D Modeling, and Immersive Geography
}

\author{
Marvin Davis \\ Thesis submitted \\ to the Eberly College of Arts and Sciences \\ at West Virginia University
in partial fulfillment of the requirements for the degree of
Master of Arts in
Geography \\ Dr. Trevor Harris, Chair \\ Dr. Jamison Conley \\ Dr. Timothy Warner \\ Department of Geology \& Geography
}

Morgantown, West Virginia

2016

Keywords: GIS, GIScience, GeoDesign, 3D Modeling, Immersion, ESRI CityEngine, Built Environment

Copyright 2016 Marvin Davis 


\title{
ABSTRACT \\ Immersive GeoDesign: Exploring the Built Environment through the Coupling of GeoDesign, 3D Modeling, and Immersive Geography
}

\author{
Marvin Davis
}

GeoDesign is a relatively new field that serves as a repurposing of many different disciplines concerned with design decisions about the built environment. More specifically, GeoDesign represents a coupling of urban planning concepts with the analytical capabilities of GIS. While GIS has been used in planning mostly in the two-dimensional realm, the built environment is three-dimensional and challenges GIS in the handling of the vertical dimension, notably in floorby-floor uses in mixed-use developments, basement-level parking, light capture, and intervisibility between structures. This research advances GeoDesign by addressing these threedimensional issues through the utilization of highly-detailed 3D models using Trimble SketchUp, the mass-model generation power of ERSI's CityEngine, and the immersive Geo-Virtual CAVE at West Virginia University to explore these issues through an Immersive GeoDesign case study of the city of Morgantown, WV. 


\section{Dedication}

The following research was made possible through the support of my mentor and my family, as they gave me the guidance necessary to move forward through the toughest of times in my academic endeavors. I want to acknowledge my mentor, Dr. Trevor Harris, who advised me in my undergraduate and graduate work at West Virginia University, along with this research. His expertise with geospatial technologies, including his research interests in 3D GIS, helped to develop my own interests that led to this research. He helped me refine my research focus and made me strive to adapt new methods to existing disciplines and technologies. Thank you for your guidance, Dr. Harris.

I am also forever grateful for the system of support provided by my parents, Brenda and Linus Davis, and my amazing wife Megan, who have all showed me the amazing things that are possible when one dreams and works hard to realize it. I was always pushed by my parents to learn everything I could and apply that knowledge to better myself and others. My family all knew the potential I had and wanted me to reach that potential, even after times it didn't seem like I believed that I was able. Throughout my academic career, I have always been interested in the world around me and the impacts of events on the world, which laid the foundation for this research. Those interests stem from an active adolescence of several different competitions, whether they were social studies fairs, the West Virginia Golden Horseshoe Contest, the Geography Bee, or even the National Academic Challenge, during all of which I had my family supporting me. My family provided me the opportunity to complete my Bachelor of Arts at West Virginia University through financial and emotional support, which allowed me to continue on to further my Master of Arts research in Immersive GeoDesign. Megan, Mom, and Dad, I dedicate this thesis to you and all the support you have given me over the years to see me go above and beyond what I ever thought possible. Thank you for everything. 


\section{Table of Contents}

Ch. 1 Introduction - p. 1

Into GeoDesign - p. 1

GeoDesign and GIS - p. 7

Immersing GeoDesign in GIS - p. 9

Research Goal \& Questions - p. 10

The Case Study - p. 12

Methods \& Tasks - p. 13

Evaluation - p. 15

Ch. 2 Literature Review - p. 17

GeoDesign - p. 17

GeoDesign and 3D GIS - p. 19

Immersive Geography - p. 20

Ch. 3 Developing an Immersive GeoDesign Environment - p. 22

Generating the 3D Models - p. 23

3D Geoprocessing - p. 28

Ch. 4 The Immersive GeoDesign Case Study of Morgantown, WV - p. 30

Background - p. 30

Data Assembly and Ingestion - p. 31

Custom SketchUp Model Importation - p. 32

Procedurally-Generated Buildings - p. 32

Ingestion into the CAVE - p. 33

Vignette 1: 3D Land Use - p. 36

Vignette 2: Parking Visualization - p. 39

Vignette 3: Sun Shadow Volume - p. 42

Vignette 4: Intervisibility - p. 45

Ch. 5 Results of the Immersive GeoDesign Case Study - p. 49

Vignette 1: 3D Land Use - p. 49 
Vignette 2: Parking Visualization - p. 51

Vignette 3: Sun Shadow Volume - p. 54

Vignette 4: Intervisibility - p. 57

Ch. 6 Evaluation and Conclusion - p. 61

Demonstration and Evaluation of Immersive GeoDesign - p. 66

Conclusion - p. 68

Bibliography - p. 70 


\section{Chapter 1: Introduction}

GeoDesign is a relatively new field that encourages a re-examination and repurposing of a number of related disciplines including geography, landscape architecture, planning, and GIS toward urban design issues (Ervin, 2011: 145; Goodchild, 2010: 8). GeoDesign integrates geography with the concepts and design decision making involved in the planning process and is especially tailored to the built environment (Steinitz, 2012: ix). GeoDesign draws heavily on both geography and the powerful tools and analytical components of GIS, and combines them with the principles of urban and regional planning to address both current and potential built environment issues (Wheeler, 2013: 58). Currently, GeoDesign resides predominantly in the two-dimensional world. However, as this study proposes, there exists opportunities to move GeoDesign into the world of three-dimensional modeling (Goodchild, 2010: 9). This research proposes a tighter coupling of GeoDesign with 3D GIS and, in particular, immersive environments to provide an integrated analytical environment better suited to the demands and needs of GeoDesign.

\section{$\underline{\text { Into GeoDesign }}$}

Carl Steinitz (2012) in A Framework for GeoDesign suggests that while it is not a new concept, the purpose of GeoDesign is to inject the perspective of geography into urban design and to change geography through design. Similarly, Goodchild (2010: 9) proposed that GeoDesign is concerned primarily with manipulating geography's forms and processes to achieve specific objectives and planning design outcomes. GeoDesign is thus closely aligned with urban and regional planning and focuses predominantly on the built environment (Wyatt 2003: 190; Flaxman, 2010). Dangermond (2010) suggested that while GeoDesign has conceptual roots in landscape architecture and environmental studies, GIScience and urban 
planning design are important for their visualization and design components. Dangermond (2010: 509) further suggested that the conjoining of planning and GIS promised to provide the basis for the integration of spatial analytics with urban design:

GeoDesign is an evolutionary step in the GIS field. While very exciting for land-use and environmental planning, GeoDesign has broad implications for virtually all professions. This methodology will be applied in many fields - by retailers who want to understand the consequences of opening or closing stores; by engineers who want to locate a road in the right location; and by utilities, farmers, foresters, law enforcement, energy companies, and military organizations, to name just a few. This approach will move GIS beyond simply describing the world as it is toward the idea of creating the future. (Italics added)

Importantly, as part of this evolution from description to creation and to simulation, Dangermond views GeoDesign as a forum for the tight coupling of geographic thinking and design principles in any examination of the built environment (Ibid.).

Ervin (2011) considered that GeoDesign "leverages the power of digital computing...to foster information-based design and provide timely feedback (sometimes 'real-time') about the implications of proposed designs, impacts and evaluations covering a larger area, greater complexity, or a longer time-frame than the immediate design proposal.” Currently Ervin (2012) notes that GeoDesign incorporates a range of methods largely based on land use mapping within a 2D digital environment. In this research, it is contended that GeoDesign is infinitely better suited to a 3D GIS modeling environment.

Steinitz (2012: 19) emphasizes that geography matters in GeoDesign: “A place has its own processes that GeoDesign will encompass, and the people of that place have decision making power." As expected, geography's place within GeoDesign is different from that of urban design, though Steinitz (ibid.: $\mathrm{x}$ ) argues that both disciplines focus on major environmental and social change, and that collaboration is crucial between the two fields. Steinitz also notes that he does not view GeoDesign as a separate scientific discipline, but rather as a field of study 
that represents the concepts, tools, and differing collaborative and disciplinary perspectives that can be brought together to analyze the geography of a place (Ibid.: 201). The concepts incorporated within GeoDesign therefore make it more than a set of tools, and the real power of GeoDesign lies perhaps in its adoption of interdisciplinary collaboration in conjunction with 3D GIS and that can generate positive change in designing and managing the built environment.

GeoDesign is thus central to urban and regional planning because it provides a basis for influencing urban design and studying the effects of alternative design scenarios. In this sense, GeoDesign is potentially valuable in addressing issues such as urban sprawl, urban decay, environmental hazards, transportation and infrastructure planning and many other aspects of the built environment. As Ervin (2012: 23) notes, "over the next 90 years we will build more urban living space than in all prior centuries combined and we had better get it right." This union between GIS and planning would entail inserting GeoDesign into urban and regional planning, and incorporating stakeholder input from government agencies, private corporations, and community citizens to develop effective urban designs. 


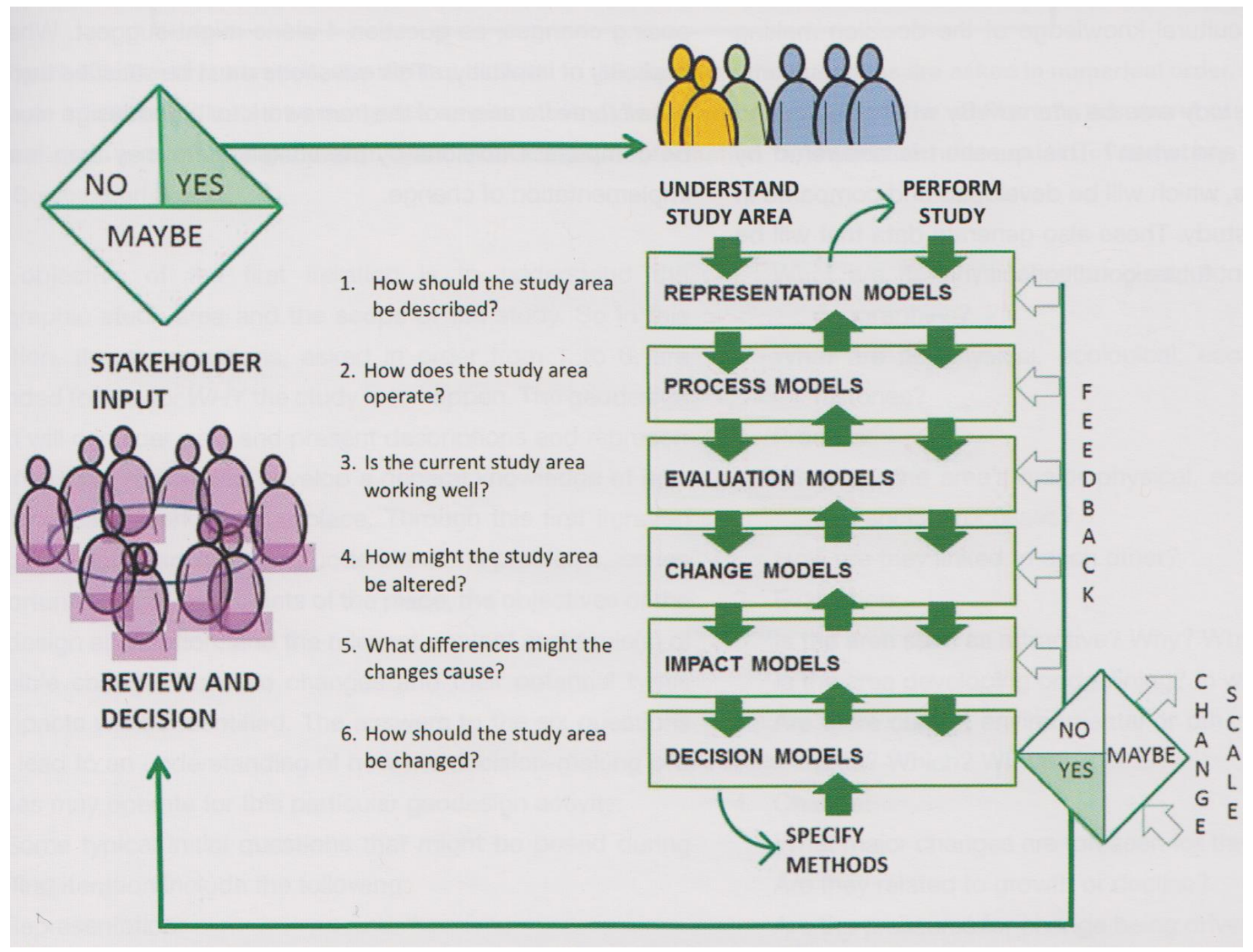

Figure 1-1: The Steinitz process of GeoDesign (Figure 3.1, Steinitz 2012: 25). 
Iteration 1: Understand The Plan ("Why?")
Iteration 2: Specify The Plan Methods (“How?")
Iteration 3: Create The Plan

("What, Where, When?")

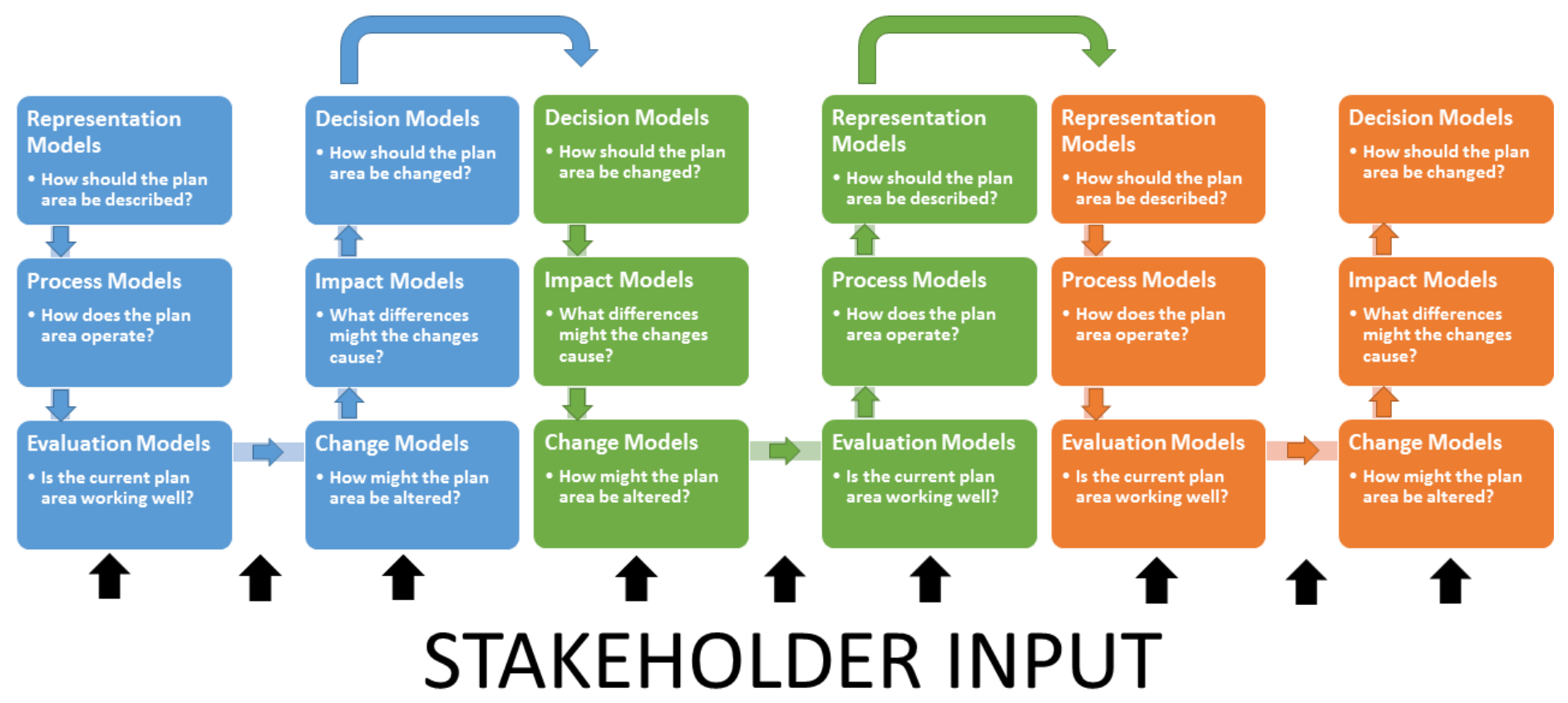

Figure 1-2: Iterations of the GeoDesign process (adapted from Steinitz 2012: 25, Figure 3.1).

Steinitz's framework for GeoDesign (Figure 1-1) captures three iterations, which have been interpreted as understanding the study area, specifying the methods of the study, and performing the study. These iterations are simplified here into the "why," the "how," and the "what, where, and when" questions in a reworked model of the iterations (Figure 1-2). These questions are ordered in such a fashion so as to address the geography, needs, methods and implementation of a study, and to point to different stages of stakeholder involvement. The first iteration, "Why?" (Figure 1-2) seeks to understand the scope of a study by describing the area and how the area and its people operates; evaluating the processes at work in the area; identifying ways in which the area might be changed; evaluating the impacts of those changes; and designing a plan as to how the area should be changed (Steinitz, 2012: 27). The second iteration, “How?” (Figure 1-2), determines the methodology employed in GeoDesign studies by 
first evaluating the impact of a plan, how the plan may be changed, if the plan works well in its current form, the process involved in executing the plan, and describing the area after the plan is implemented (Ibid., 28). The third and final iteration, the "What? Where? When?" questions (Figure 1-2), comprises implementing the plan according to the methods devised in the second iteration (Ibid., 30). These "Why?" "How?" and "What, Where, When?" questions are interpreted through the three iterations of Steinitz's model by using representational models based on data from the study, the process models (assessment analyses of the study), the evaluation models (which are dependent upon the geography of the study area), the change models (created and compared during the study), the impact models (assessments produced by the process models under changed conditions), and the decision models based especially on professional input from the fields of planning, design and GIS (Ibid., 26). Throughout the process of GeoDesign, stakeholder feedback is necessary as a means of providing efficient and effective decisions during any step of the three iterations and from affirmation to alteration of the plans. At each stage of the three iterations of the GeoDesign process, the models are considered by stakeholders for review, comment, and possibly decision. If a decision cannot be achieved, stakeholder input can again be incorporated into further reviews of the three iterations to produce new models for stakeholder consideration. The study undertaken here into Immersive GeoDesign utilizes the representation, process, change, evaluation, impact, and decision models within the iterative Steinitz process of GeoDesign through the use of 3D GIS modeling in an immersive environment. 


\section{$\underline{\text { GeoDesign and GIS }}$}

GeoDesign relies heavily on GIS. The Steinitz GeoDesign process implicitly builds on the mapping and spatial analysis components of GIS and almost exclusively in the twodimensional realm (Figure 1-3).

\section{Iteration 1: Understand The Plan (“Why?")}

Iteration 2: Specify The Plan Methods (“How?")
Iteration 3: Create The Plan

("What, Where, When?")

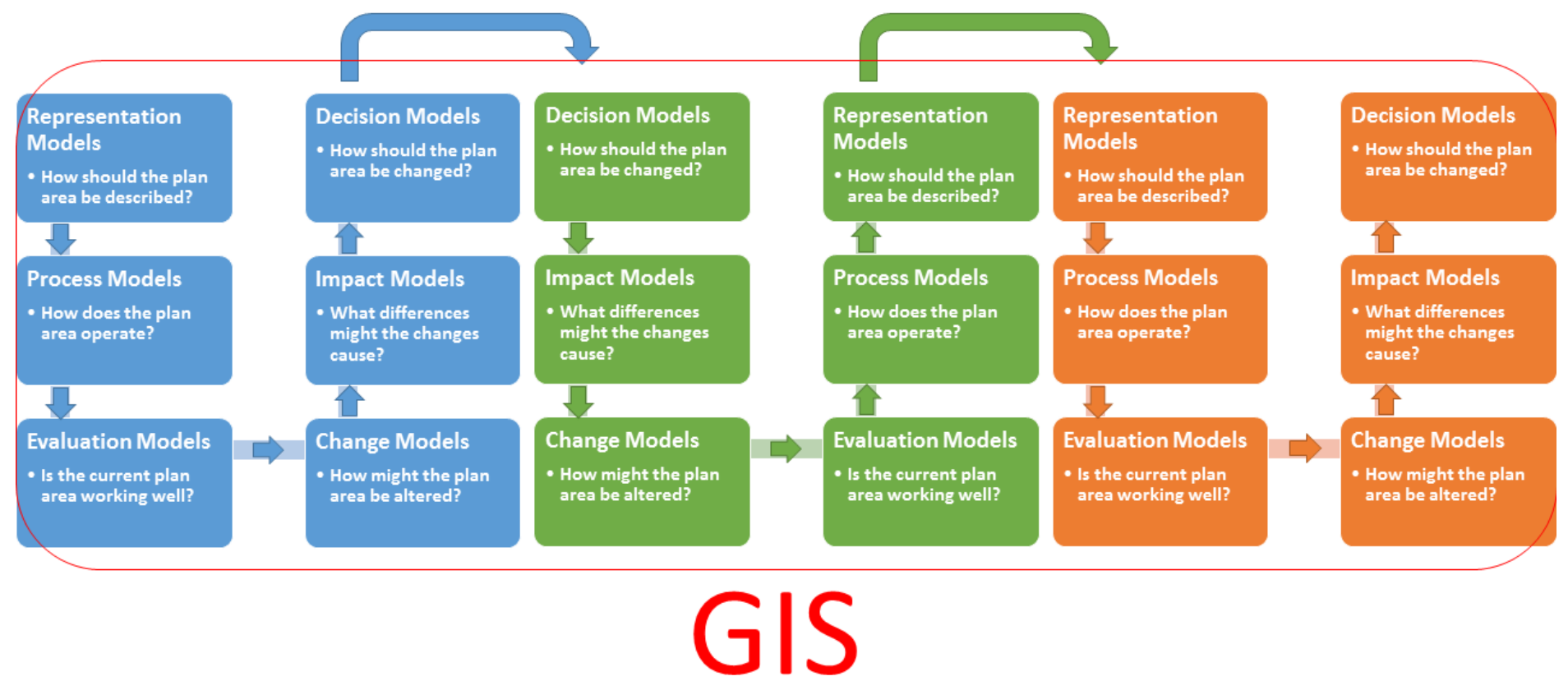

Figure 1-3: The iterations of the GeoDesign process necessitate the use of GIS (Adapted from Figure 3.1, Steinitz 2012, 25).

While GIS is relatively well known, there is generally less known about GeoDesign applications in GIS (Wyatt, 2003: 367). To date, two-dimensional mapping has provided the basis for GeoDesign, and especially in the form of planning maps for development purposes. One of the strongest fundamentals of GIS lies in supporting design decisions by overlaying map layers which represent the multiple factors important in the design decision (Goodchild, 2010: 
7). GIS thus provides a powerful base for implementing GeoDesign methods and for mapping, visualization, and analysis.

The ability to create data layers that combine terrain, land cover, building models, slope and aspect are essential for effective GeoDesign and clearly GIS is well suited to this need (Harding, 2010: 24). However, two-dimensional mapping is very restrictive when depicting and analyzing building heights, building volumes, line-of-sight analyses, terrain, slope, and aspect, and yet all these are vital issues central to GeoDesign (Yin, 2010: 420). Arguably, GeoDesign calls for 3D modeling that allows users to create a multi-dimensional built environment. Schaller (2012: 236) specifically notes that the assessment of landscape structure and scenery is important in GeoDesign, and that 3D landscape modeling is an important element of GeoDesign that enhances design quality. To this end, the complex requirements of GeoDesign in addition to GIS could also draw upon remote sensing data and LiDAR, pictometry, high resolution satellite data, and stereo camera images (Schaller 2012: 236).

A 3D interactive environment can offer intuitive ways to view and analyze the built environment. Yin (2010: 421) notes that 2D mapping provides limited perspectives whereas 3D models provide users with the ability to navigate a study area, fly over streets and buildings, or rotate 360 degrees to examine details of buildings or the spaces between them. Recent initiatives in GIS have seen a move from the 2D map to 3D block modeling, such as within ESRI's CityEngine, with its ability to extrude building plots and street line data. CityEngine enables extensive digital urban landscapes to be created within a highly-realistic visual environment based on the power of procedural rules that allow for advanced analysis and modeling (Wyatt 2003: 190). The models created within CityEngine have the potential to provide GeoDesign with an analytical environment capable of interfacing 3D GIS with complex physical and social 
geographies and the design components of the "real" world built environment (Ibid.).

Importantly, new tools and software are now available, such as Trimble SketchUp and ESRI

CityEngine, which enables 3D models to be created with relative ease. Once created, the models, usually stored in KML format or as a Collada extension, can be exported to a number of display programs such as ESRI's ArcScene or Google Earth. ArcScene is an extremely valuable application for integration with GeoDesign because of its extensive 3D analytical geoprocessing toolset.

\section{Immersing GeoDesign in GIS}

Immersive technologies provide a potentially valuable environment within which to explore GeoDesign from the perspective of "being in the scene." Immersive 3D GIS moves from the geovisualization of "flat" displays to a sense of being enveloped or immersed within a highly-realistic virtual world in which the senses of the user are greatly enhanced and the user experiences a three dimensional world with all of its multiple perspectives and viewpoints. While Harding (2010: 24) argues for audio immersion for use in transportation planning, he also makes a case for the equivalent of a multi-sensory Immersive GIS in GeoDesign. This form of geovisualization draws upon multiple senses (mainly visual, but also auditory, haptic, and olfactory) to enable users to experience a virtual 3D world that can be displayed in seeming realworld detail. Such a system is well-suited for pursuing GeoDesign for the built environment.

The CAVE, (CAVE Automatic Virtual Environment) is a system comprised of up to six large wall screens that provide a powerful immersive environment. Immersion is accomplished through a complex network of computers, projectors, stereoscopy, and graphical imagery. The four screens of the WVU CAVE each have short-throw projectors that project images in stereoscopic 3D. These projectors receive imagery from powerful graphics cards, which parse 
information to the render node from the master node computer. Through the use of stereo image emitters and active 3D glasses, an image can be viewed in stereoscopic 3D and enhanced by immersive capabilities that provide a very real sense of immersion and of "being there."

GeoDesign is greatly enhanced when brought into a CAVE for a range of applications that can focus on design implications involved in transportation, infrastructure, sustainability, urban decay, development, and a host of others. GeoDesign in a CAVE potentially provides planners, analysts, and stakeholders, such as residents and developers, the ability to experience the built environment and to model proposed changes to that environment. Analysts are able to see the 3D geography of the built environment and pursue GeoDesign issues. In addition to visualizing the 3D built environment, using the procedural rules within CityEngine, planners and stakeholders can potentially address a multitude of questions and issues in a GeoDesign model such as the model's financial details, space requirements, extent of required parking, number of residents or density, utilities or sustainability requirements, and many other issues. These different factors of the modeled urban form can be programmed to automatically generate revised figures should changes be made. In summation, utilizing 3D GIS modeling and immersive technologies can advance GeoDesign by providing an enhanced virtual platform for the representation, alteration, impact evaluation and decision making models envisaged by the Steinitz process of GeoDesign.

\section{$\underline{\text { Research Goal \& Questions }}$}

This research sought to implement and evaluate GeoDesign concepts and practices within an immersive CAVE environment using GIS and procedural 3D modeling. This exploratory work was pursued using a case study based on Morgantown, West Virginia. Specifically, the research addressed the following goals, questions, and tasks: 
1) First, the research undertook a review of the concepts and practices of GeoDesign.

2) The research then addressed ways in which GeoDesign could be integrated with GIS and 3D modeling.

3) Third, the research sought to utilize the procedural rule capability of CityEngine to mass produce 3D models of the built environment to support GeoDesign.

4) The research then explored how GeoDesign could be implemented within a 3D stereo immersive environment.

5) Next, the research undertook a case study of GeoDesign in the built environment of Morgantown, WV. The case study focused on implementing four vignettes that demonstrated differing functional aspects of a 3D enabled GeoDesign. The four vignettes comprised:

a. Create 3D models in CityEngine to define and display a 3D land use representation of retail, residential, and office space

b. Demonstrate the value of the procedural rules in CityEngine for performing specific planning tasks in GeoDesign such as automating parking requirements based on building occupancy

c. Demonstrate how issues of light capture and shadow that might arise from proposed building developments and that might impact existing structures can be explored in 3D GIS

d. Generate, visualize and interpret 3D intervisibility between proposed and existing building structures.

6) Finally, assess and evaluate the benefits and limitations of coupling GeoDesign with 3D GIS modeling in an immersive environment. The evaluation is based on a demonstration 
of the system to professionals working in the field of urban and regional planning and specialist graduate students in urban and regional planning, GIS, and immersive geography.

\section{The Case Study}

Morgantown was selected as a case study for this research because it is easily accessible and well-resourced with spatial data. As with many urban environments, Morgantown possesses its own planning and design issues that are suitable for Immersive GeoDesign. The terrain surrounding Morgantown places considerable limitations on new development. Previously blighted areas of the city, such as the Wharf District, have been gentrified and seen large former warehouses converted into office and retail space. Sunnyside is undergoing a similar transition as single-family detached houses that were subsequently converted into multi-unit apartments have become blighted due to lack of investment, rental domination, and student ghettoization. Presently, with the advent of large apartment complexes within city limits and to the north of Morgantown and outside city limits greater vehicular traffic and congestion has resulted along with an increased demand for already limited parking in the city. With further large-scale developments envisioned and created in Sunnyside, Morgantown provides a valuable case study for GeoDesign.

Through the geoprocessing tools available in ESRI's ArcGIS, the case study model was analyzed within an immersive stereoscopic 3D environment. The four exemplar studies, or vignettes, were undertaken to explore and demonstrate the display and analytical capabilities of Immersive GeoDesign. The first vignette used zoning plans to define and display 3D land use whereby retail, residential units, and office functions were identified in three dimensions. Typically, a non-Euclidean method of zoning is used in planning by labeling the building 
footprint as simply "mixed" or "multi-use" on a 2D plan or map. In the real-world, zoning is typically done on a floor-by-floor basis, which can only be effectively visualized in a 3D form. The ability to visualize 3D buildings is powerful and helps improve an understanding of each individual floor and the differing functions of those floors. A second vignette, based on building occupancy and floor space, used CityEngine procedural rules to automatically calculate the amount of space required for parking for both proposed and existing buildings. This is a significant issue in urban planning and for Morgantown.

The final two vignettes examined potential light capture by new high-rise buildings in Morgantown using Sun Shadow Volume analysis and intervisibility procedures. Light capture is essential for achieving "green" certification for buildings, as light capture is positive for both solar power, natural lighting, and human aesthetics. Identifying the shadow volumes created at minimum and maximum sun angles throughout the year is a powerful method to study the impacts of proposed high-rise buildings. If a building relies on light capture for energy or lighting, then a nearby newly constructed high-rise building could cast a shadow and impede solar capture. The information obtained from intervisibility analyses can be essential to stakeholders for mitigating visual intrusion from a proposed development. Intervisibility is valuable in assessing not only the potential visual impact of a building on neighboring structures but also to ensure some degree of conformity of building height in a neighborhood. To perform intervisibility in the built environment implicitly requires a 3D analytical environment.

\section{$\underline{\text { Methods \& Tasks }}$}

To pursue the Immersive GeoDesign case study for this research, the following tasks were performed to create a 3D GIS model of the Morgantown built environment, and to implement the model in the CAVE for visualization and analysis. The first task was to integrate 
the following data layers: three-foot resolution aerial imagery, obtained from the West Virginia GIS Technical Center (WVGISTC); two-foot digital elevation model (DEM) of the City of Morgantown for terrain generation (WVGISTC); and building footprint polygons for extruding the built environment (City of Morgantown). The building footprints were subsequently extruded to create 3D models of buildings in Morgantown using ESRI CityEngine procedural rules. The rules used zoning codes to classify the functions of the $3 \mathrm{D}$ models and associated rendering for uses such as residential, commercial, and industrial. Randomized roof heights based on each building's zoning code were also applied. The extruded building models were then rendered through CityEngine's procedural rules that assigned textures to non-critical buildings in Morgantown based on the zoning codes. To achieve geosimilarity, the procedural rules randomized building textures between different generic façade and roof textures based on each zoning code to prevent a uniform visual appearance to the buildings in Morgantown.

Trimble SketchUp was used to create the detailed individual customized buildings and landmark structures within Morgantown. The individual models were imported directly into CityEngine from SketchUp as KML files and the locational accuracy of their urban footprint was verified via the base aerial imagery. Models of the "urban fabric" such as trees, vegetation, greenery, chairs, and lamp poles were added to increase realism of the built environment. Once the 'georealistic' SketchUp models were imported and the 'geosimilar' CityEngine models were procedurally generated, the virtual built environment was verified for accuracy in building heights, textures, and general appearance based on field inspection.

After verification, the models were ingested into the CAVE for display, navigation, and analysis. Three software platforms were used which provided differing levels of visualization within the CAVE. ArcScene provided the immersive experience sought as it is parsed to the four 
wall CAVE through Conduit software. ArcGlobe provided a caching feature that greatly improved rendering of the virtual built environment, but was only available in stereo 3D through NVIDIA's Mosaic software, which did not provide as strong an immersive experience as Conduit. CityEngine was tested in the CAVE but was also only available within Mosaic. In the end, ArcScene was selected as the platform of choice for scene display within the CAVE. Once the virtual built environment was ingested into the CAVE, the four case study vignettes were pursued. Zoning plans were used to define and display in 3D the separate functions of retail, residential, and office space in mixed use buildings. The amount of parking space required was calculated based on building occupancy through procedural rules established in CityEngine. Light capture and permanent shadow created by high-rise development were visualized through the use of the Sun Shadow Volume tool in ArcToolbox. Intervisibility analysis was then performed on downtown Morgantown and compared to a 2D Visibility analysis as part of the final vignette. The rendered built environment and vignettes were shown in a presentation and demonstration with the goal of collecting anecdotal evidence towards the evaluation of the research.

\section{$\underline{\text { Evaluation }}$}

The final step of this research comprised the implementation of GeoDesign examples within the 3D CAVE environment and a critical evaluation of each vignette of the case study. The first part of the evaluation focused on demonstrating the integration of technologies to support Immersive GeoDesign, and including GIS, 3D modeling, and the CAVE. The case study's four vignettes that elaborated on important facets of Immersive GeoDesign were evaluated on the basis of the following: 1) the value of a procedural rule-based CityEngine in the rapid prototyping and generation of a virtual built environment necessary for GeoDesign; 2) the 
constraints of display quality for visualizing and navigating the virtual built environment; 3) the value of $3 \mathrm{D}$ modeling in the CAVE in providing an intuitive interpretation of the built environment compared to a 2D representation; 4) the benefits of zoning a development by floors using procedural rules; and 5) the advantages and disadvantages of using geoprocessing tools for GeoDesign within the CAVE. Finally, after the CAVE demonstration and discussion with professionals in the field of planning and GIS, the comments obtained were used to reflect on and evaluate Immersive GeoDesign and its value in advancing GeoDesign beyond that which is currently possible based on traditional 2D GIS. 


\section{Chapter 2: The Case for GeoDesign}

As a field of inquiry, GeoDesign is in its infancy. An emerging field of GeoDesign offers opportunities for geographers, planners, landscape architects, engineers, government officials, and others to influence the evolution of GeoDesign. Prior to coining the term, urban planning and urban design were conceived and practiced for years as somewhat separate elements pursued by urban planners and landscape architects. GIS had a substantial impact in creating GeoDesign as an effective tool for the mapping and visualizing urban design and planning. GeoDesign is a repurposing and integration of these combined concepts and GIS tools intended to improve urban design decision making. Carl Steinitz (2012), who coined the term, in grandiose fashion defines GeoDesign as "changing geography by design." Steinitz (ibid) prefaces his A Framework for GeoDesign by pointing out that the noun and verb definitions of "design" also contain the keywords "plan," "purpose," and "future"; the same as used to define urban planning and landscape architecture. However, GeoDesign seeks to incorporate design through analyzing and optimizing the geography of built environments through the power of GIS.

Dangermond (2010, 506) claims, "Much like GIS and environmental planning before it, GeoDesign takes an interdisciplinary, synergistic approach to solving critical problems and optimizing location, orientation, and features of projects both local and global in scale." Ervin (2011) focuses more on the technology of GeoDesign, adding that "GeoDesign enhances traditional Environmental Planning and Design activities with the power of modern computing, communications, and collaboration technologies, providing on-demand simulations and impact analyses to enable a more effective and responsible integration of scientific knowledge and societal values into the design of alternative futures." Both Dangermond and Ervin see GeoDesign as a coupling of GIS and planning for the purpose of improving design decisions. 
Tomlin (2011) suggested that "much of the current discussion about GeoDesign has been oriented toward the ways in which it can be supported through the use of GIS and - perhaps more importantly - the ways in which GIS might be extended or refined to better assume that role." Steinitz (2012) stresses not only GIS but geography as the key to GeoDesign. While GIS is, and will continue to be, an important component in support of GeoDesign, there appears to be a possible misconception that all of geography is GIS, rather than that GIS is a part of a greater geographic discipline. A marriage of geography with design, according to Steinitz, would embrace the entire family of geography, both human geography and physical geography, not just GIS. In much the same way, cartography is important to GIS and GeoDesign, but not all aspects of GeoDesign are cartographic (Goodchild 2010: 14). Utilizing only the modeling and analytical environment of GIS without incorporating the human and physical geographic knowledge that are necessary to understand and analyze an urban landscape arguably cannot lead to the improved design decisions desired by the proponents of GeoDesign.

Urban and regional planning is strengthened through GeoDesign as plans are optimized and data is produced and used to better inform the stakeholders. Stakeholders are important to GeoDesign. As Ervin $(2012,29)$ stresses, “As we engage in transforming our planet and our societies, we will inevitably and repeatedly come up against the complications of cultural diversity and multiple points of view." Informed decision making involving multiple stakeholders is a core element of GeoDesign. In addition, Goodchild (2010: 10) suggests GeoDesign is "planning informed by scientific knowledge of how the world works, expressed in GIS-based simulations.” Goodchild believes that GeoDesign and GIS provide an additional dimension to the domain of urban planning. Interestingly, GeoDesign can also advance GIS by its inherent need to explore future, rather than solely present day, conditions. Dangermond 
(2010: 509) notes that to date GIS has been heavily focused on describing the geography of a landscape. The ability to model potential consequences for decisions concerning the urban setting can be used for more than description band to identify alternative trajectories and outcomes.

Much of what GIS has contributed to GeoDesign thus far has resided in the twodimensional realm (Flaxman 2009: 28), making it difficult to address the important threedimensional characteristics of the built environment. This leaves a void to be filled through the use of 3D GIS modeling and analysis to adequately represent and design the built environment. Schaller (2012: 236) suggests that data such as RADAR, LiDAR, and high resolution satellite data, along with automated draping technologies for 3D objects are important in allowing synthetic and photorealistic 3D landscape visualizations and simulations to be created that are capable of displaying alternative planning scenarios. Schaller also makes the point that the assessment of design impacts on landscape structure and scenery is an important requirement for GeoDesign, and 3D landscape modeling is thus an important tool to speed GeoDesign processes and support ad hoc design decisions (ibid). Koninger and Bartel (1998: 79) suggest that the increased use of GIS and CAD will make 3D data more available and allow planners to emphasize the modeling of 3D urban space. Much of what Koninger and Bartel allude to as 3D urban GIS is actually being realized with the advent of GeoDesign aided by improvements in computer hardware and 3D data availability.

According to Groger and Plumer (2009: 138), the complexity required to construct 3D structure models differ depending on the specific application. Advanced applications of 3D GIS do require more effective models, particularly applications within GeoDesign. Through the research performed here in Immersive GeoDesign, the software employs both digital surface 
models and 3D building models in combination to create and analyze Morgantown's built environment.

Immersive geography is still, like GeoDesign, an emerging field as technology continues to advance to the point that immersive technologies become more powerful and cost effective. Immersion refers to stereoscopic 3D immersion. Stereoscopy provides an illusion of depth that is created by presenting a slightly different image to each eye (Buchroithner 2012: 85). Ervin (2012: 25) predicts that augmented reality interfaces and immersive displays will become more available and useful in furthering GeoDesign. Moellering admits that with "true" 3D visualization, there should be more work undertaken to utilize and extend analytical visualization, which Immersive GeoDesign seeks to provide (Buchroithner 2012: 18). The visual analytics of Immersive GeoDesign offers a powerful concept and method to improve urban design decisions.

Harding (2010: 25) sees the potential of expanding immersive environments in planning through the utilization of 3D graphics and stereoscopic vision technology along with haptics (touch) and audio immersion. A component of 3D immersive environments is the interface between the user and the system which goes beyond traditional mouse and keyboard navigation: "the benefits of multi-modal (visual, audio, haptics, smell) information presentation include the merging of mutual information [synergy, data fusion], increased robustness via redundant mapping of the same information to several modalities, and increased performance due to increased sensory bandwidth" (Ibid). Harding further suggests that, "by channeling information through multiple senses, more information can be processed simultaneously and potentially more effectively." While Harding's work focused on 2D highway planning, the author did offer a future scenario which linked GIS and planning within immersive stereo 3D environments 
coupled to haptic and audio interfaces with what he saw as obvious benefits for GeoDesign

(ibid., 36). The coupling of immersion and 3D modeling are a primary theme underpinning this GeoDesign research. 


\section{Chapter 3 Developing a 3D Immersive GeoDesign Environment}

The ability to create and manipulate spatial data and to then transfer that data across platforms for extrusion into a virtual 3D built environment must be efficient and effective. The software involved in this research is critical to enabling examination of the built environment for GeoDesign. Trimble's SketchUp is capable of creating individual highly detailed models of buildings which contribute to the geosimilarity and georealism needed for Immersive GeoDesign (http://help.SketchUp.com/en/article/115430). While very effective at creating individualized and geosimilar models, SketchUp requires the "manual" construction of the digital model, which can add considerably to the time and resources needed for a project to be completed. To improve the efficiency in modeling extensive built environments, such as towns or cities, ESRI's CityEngine enables mass production of building models through the application of automated procedural rules

(http://cehelp.esri.com/help/topic/com.procedural.cityengine.help/html/quickstart/overview.html)

The combination of SketchUp with CityEngine's procedural rules, enables users to create an extensive 3D built environment. In addition, it is possible to link CityEngine and its 3D modeling capability to the geoprocessing tools in ArcGIS by exporting data into an ESRI geodatabase. Another benefit of using ArcScene in this research is its compatibility with Mechdyne's Conduit software, which allows the scene to be projected into the stereo immersive CAVE. 


\section{Generating the 3D Models}

Trimble SketchUp enables the creation of highly realistic individual 3D models of buildings. SketchUp is particularly powerful when modeling unique buildings (Figure 3-1) and landmark buildings where greater attention to detail is required. Immersive GeoDesign invariably requires as much photo realism as the hardware, software and resources will allow in order to realistically mimic the built environment. SketchUp is a key piece of software in creating georealistic 3D models, but it is a time consuming process.

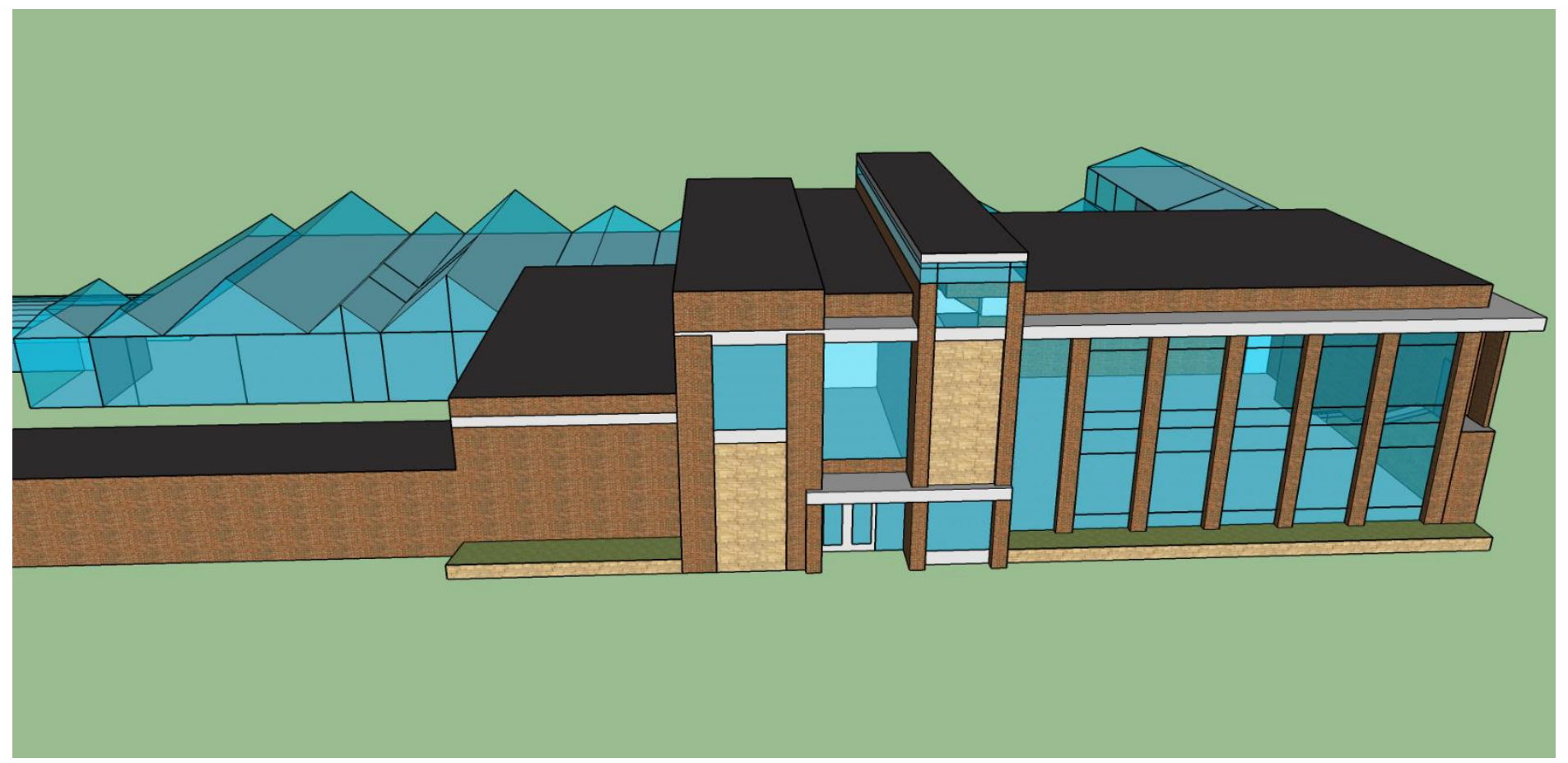

Figure 3-1: A 3D model of WVU's new Evansdale Campus Greenhouse in SketchUp based on artist's renderings.

SketchUp offers users several different methods to create and modify 3D models. All models start as a blank space with $\mathrm{X}-\mathrm{Y}-\mathrm{Z}$ axes for the user to identify the extent of the three bounding dimensions. In addition to drawing tools, SketchUp offers an extensive library of 
colors and material textures that can be applied to render a model, as well as an option to upload user-created content, such as photo facades for buildings (Figure 3-1) (http://help.SketchUp.com/en/article/115430). Creating model components, or repetitive features such as doors, windows, and light posts among others, is important in saving time and resources in creating multiple $3 \mathrm{D}$ models. In addition, when creating these models users have a wide assortment of components already constructed by other users and stored in the SketchUp 3D Warehouse, which can also improve efficiency in the model creation process (https://3dwarehouse.SketchUp.com/?redirect). A link to Google Maps provides users with the option to attach the model to a geographic location so that the model will be accurately located in the area being studied.

While there are several methods that improve the efficiency in creating 3D building models within SketchUp, use of the program becomes somewhat impractical when faced with the entirety of a large urban environment because of the sheer number of buildings to be modeled. The modeling and rendering environment within SketchUp is tailored towards individual 3D building models rather than large and complex built-up areas. Another limitation of SketchUp is its inability to retain the spatial locations of separate individual models within its own platform when importing them into a virtual built environment. SketchUp does not provide any geoprocessing functions that are demanded by GeoDesign. Nonetheless, SketchUp is a powerful 3D modeling package that provides georealistic models for embedding in a rendered 3D built environment.

ESRI's CityEngine is a powerful software system not least because of its ability to mass produce 3D models through the use of Computer Generated Architecture (CGA) procedural rules (http://cehelp.esri.com/help/topic/com.procedural.cityengine.help/html/quickstart/usingcga.html) 
. These procedural rules use geospatial data and attributes to automatically extrude 3D models based on parameters defined by the user. The ability to mass produce 3D models is clearly valuable when creating a 3D digital visualization of a built environment comprising many buildings. With the push for "smart" cities and efficient design, CityEngine provides a critical asset to not only model the existing environment, but to visualize future environments using automated procedural rules.

The procedural rules contained within a CGA script file are the real power behind CityEngine. These rules are input into CityEngine by the user to define the shape, size, color, and texture of the 3D models to be generated. Rules can be created for any number of features, such as doors, windows, roofs, overhangs, setbacks, orientation, and rendering. Every CGA file has a specified "start rule" which CityEngine recognizes to begin the process of extruding the 3D building models from the 2D data. A key function of procedural rules is known as a "case" statement, where the user provides very detailed instructions as to how CityEngine should extrude, color, and photo texture the 3D models. As shown in Figure 3-2, different rules can be applied to buildings based on data attributes and IDs such that one façade can be used for multiple modeled buildings. Each sub-rule specifies different window and door patterns, exterior materials, roof heights, and roof materials. Once implemented, CityEngine can automatically generate 3D models to populate large and complex built environments (Figure 3-3). The time necessary to create the procedural models is more than offset when mass generated buildings are required. One potential sacrifice though in mass modeling is the lesser detail possible in the models, though detail can be improved in models requiring greater specificity to acceptable levels by the user through adding more rules (and thereby greater time and effort) to the CGA script. 
\#The "Lot" rule (established by the --> symbol succeeding the rule name) is known as the start rule, which is what CityEngine

\#knows to begin with when the procedural rule script is run. This rule's purpose is to extrude the building footprints into 3D models,

\#then set the appropriate rules to their corresponding land use codes (present in the attribute table of the building footprints shapefile).

A "case" statement is used to set the rules according to the "LandUse" attribute,

case LandUse $==$ "PRO" :

cleanupGeometry(all, 0.1) extrude (BuildingHeight) comp (f) f front : prozone | side : prozone | top: proRoof

\#This first case statement will extrude the building footprint then establish the rules needed to render the structure. The cleanupgeometry() \#function merges all lines within a threshold of 0.1 meters to improve rendering performance of CityEngine and to avoid any possible errors \#created by stray vertices in the footprint. The model is then extruded by the value set in the "BuildingHeight" attribute earlier in the script. \#The comp(f) function splits the building into components, specifically in this script by faces (f). Each face has a corresponding rule for

\#rendering by solid color or photo-texture. The rules above create a solid color render for the model as part of the 3D land use vignette of the case study. case LandUse $==" 2 "$ : cleanupgeometry (all, 0.1) extrude (Height) comp (f) \{ front : reszone | side : reszone | top: resRoof\}

case LandUse $==" 3 "$ : cleanupgeometry(all, 0.1) extrude (Height) comp (f) \{ side : reszone | top: resRoof\}

case LandUse $==" \mathrm{R}-1 "$ : cleanupGeometry(all, 0.1) extrude (Height) comp (f) \{front : resZone | side : reszone | top: resRoof\} se LandUse $==" \mathrm{R}-1 \mathrm{~A} "$ :

cleanupgeometry(all, 0.1) extrude (Height) comp (f) \{ front : reszone | side : reszone | top: resRoof

case LandUse $==" \mathrm{R}-2 \mathrm{n}$ :

cleanupgeometry (all, 0.1) extrude $(\operatorname{rand}(5,10)$ ) comp (f) \{ front : reszone | side : reszone | top: resRoof\}

case LandUse $==" \mathrm{R}-3 "$ :

cleanupGeometry (all, 0.1$)$ extrude $(\operatorname{rand}(5,10))$ comp (f) f front : reszone | side : reszone | top: resRoof

ase LandUse $==$ "R- 3a" :

cleanupGeometry(all, 0.1) extrude (rand $(5,10)$ ) comp (f) \{ front : reszone | side : reszone | top: proRoof

case LandUse $==$ "PRO" :

cleanupgeometry(all, 0.1) extrude (BuildingHeight) comp (f) \{ front : prozone | side : prozone | top: proRoof\}

case LandUse $==" B-1 "$;

cleanupGeometry(all, 0.1) extrude (Genericheight) comp (f) f front : profZone | side : profZone | top: profRoof

case LandUse $==$ "B- $2 "$

cleanupGeometry(all, 0.1) extrude (GenericHeight) comp (f) \{ front : profZone | side : profZone | top: profRoof\}

case LandUse $==" \mathrm{~B}-4 "$ ",

cleanupgeometry(all, 0.1) extrude (GenericHeight) comp (f) \{ front : profZone | side : profZone I top: profRoof\}

"B- 5"

cleanupgeometry (all, 0.1) extrude (GenericHeight) comp (f) f front : profzone | side : profzone | top: profRoof\}

case LandUse $==$ "OI" :

cleanupgeometry (all, 0.1$)$ extrude (rand $(10,15))$ comp (f) \{front : offZone | side : offZone | top: offRoof\}

cleanupgeometry (al1, 0.1) extrude (rand(8,12)) comp (f) f front : indzone | side : indzone | top: indRoof

dUse $==$ "IND"

cleanupgeometry(all, 0.1 ) extrude (rand(8,12)) comp (f) f front : indzone | side : indzone | top: indRoof

cleanupgeometry (all, 0.1) extrude (rand $(5,10)$ ) comp (f) \{ front : prozone | side : prozone | top: proRoof

case LandUse $==$ "Honors"

cleanupGeometry (all, 0.1 ) extrude (25) comp (f) ifront : reszone | side : reszone | top: proRoof

cleanupGeometry (all, 0.1) extrude (35) comp (f) \{front : reszone | side : reszone | top: proRoof

cleanupgeometry $(a 11,0.1)$ extrude (rand $(8,12)$ ) comp (f) \{ front : indzone | side : indzone | top: indRoof

\#A case statement, or multiple case statements, must have an "esle" statement to close the loop and allow CityEngine to move forward to the next rule. else :

cleanupgeometry (al1, 0.1) extrude ( $\operatorname{rand}(5,15))$ comp (f) \{ front : campZone | side : campzone | top: campRoof\}

Figure 3-2: An example of a "case" statement in a procedural CGA rule script in CityEngine. 


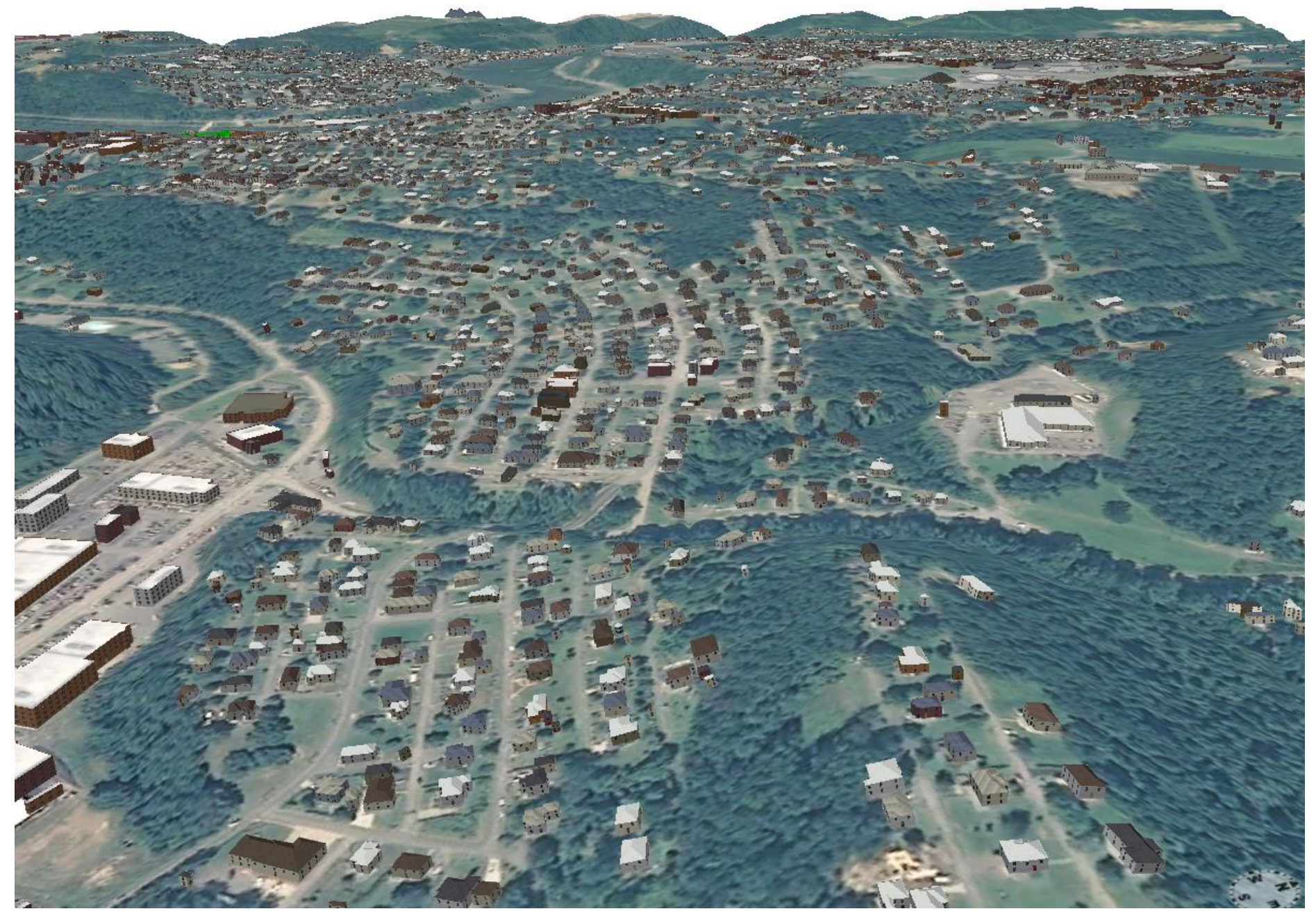

Figure 3-3: Example of a procedurally generated 3D townscape within CityEngine.

CityEngine is able to import a wide variety of data types into its workspace to create a large scale 3D model of the build environment

(http://cehelp.esri.com/help/topic/com.procedural.cityengine.help/html/manual/import/import_ov erview.html). Along with georeferenced imagery and terrain import capability, two crucial data types compatible with CityEngine are ArcGIS geodatabases and the SketchUp .kmz export format. This compatibility allows for a balance between lesser detailed, mass-generated 
buildings and higher-detailed, individualized buildings within the modeled built environment (Figure 3-4).

\section{Low Level of Detail}

Geosimilarity-oriented

- Application: CityEngine

- Procedurally Generated Models

- Many Models Created in Lesser Time

- Good for Background, Non-Focal Buildings
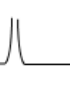

Georealism-oriented

- Application: Sketchup

- Manual Model Creation

- More Time Required for Creation

- Good for Focal Buildings and Landmarks

Figure 3-4: A level of detail comparison between SketchUp and CityEngine when modeling the built environment.

\section{D Geoprocessing}

ESRI's 3D Analyst and ArcScene provides a geoprocessing and analytical capability that cannot be provided explicitly within either SketchUp or CityEngine. The 3D Analyst toolbox contains valuable geoprocessing tools, such as line-of-sight, intervisibility, sun shadow, viewshed, and other functions that operate on 3D models (http://resources.arcgis.com/en/help/main/10.2/00q8/00q800000003000000.htm). CityEngine can export 3D model scenes to ArcScene as a geodatabase in order for the analytical tools to be 
applied. Navigation within ArcScene allows for easy exploration of the modeled environment. The ease of navigation is extremely important when interacting with scenes in an immersive environment.

Significantly, however, ArcScene does not have a feature caching capability and large datasets, especially ones created within CityEngine, overwhelm the system since the entire scene data must be loaded into the system's memory, not just the data in the current extent shown within the view window. ArcGlobe, however, does offer caching which is valuable when visualizing a larger urban extent such as Greater Morgantown, WV (http://resources.arcgis.com/en/help/main/10.2/00q8/00q800000003000000.htm). The downside to using ArcGlobe is that it is not currently supported by Conduit software within the WVU CAVE, but utilizing the Mosaic software by NVIDIA is an alternative route for achieving stereoscopic 3D visualization within the CAVE. SketchUp, CityEngine, and ArcScene are thus crucial parts of the whole system that is required to advance Immersive GeoDesign. SketchUp's attention to detail, CityEngine's iterative and automated ability to mass produce building models, coupled with 3D Analyst and ArcScene's geoprocessing and visualization capabilities, form a trinity to support Immersive GeoDesign. 


\section{Chapter 4 The Immersive GeoDesign Case Study of Morgantown, WV}

Morgantown, WV was chosen as a suitable location to conduct a case study for Immersive GeoDesign due to the large amounts of spatial data available for the city and the urban design issues that could be pursued by way of demonstration. Morgantown is home to West Virginia University (WVU) and the West Virginia GIS Technical Center (WVGISTC), which is a repository for spatial data for the entire state of West Virginia. The WVGISTC possesses several high-quality datasets that are critical to the creation of a highly-detailed, immersive Morgantown virtual built environment. Morgantown is experiencing aggressive redevelopment and expansion due to the growth in student numbers attending WVU, as well as by people employed by federal agencies. A city that once had an industrial base has been transformed into a student-populated college town that has created high demand for housing, which has in turn put a not inconsiderable strain on the city's infrastructure. The issues faced by Morgantown are prime candidates to be addressed through Immersive GeoDesign and 3D visualization as single-family, detached houses give way to large apartment complexes with concomitant issues concerning building light capture, shadow, visual intrusion, land use conflicts, and parking demands. For the purposes of separating the results from the method the outcomes of each vignette study are discussed and displayed in Chapter 5.

\section{$\underline{\text { Background }}$}

Morgantown was once a heavily industrialized town situated on the Monongahela River and included residential neighborhoods such as Sunnyside and industrial centers such as the Wharf District. As WVU expanded, the student population found affordable rental housing in the detached houses adjacent to former industrialized sites. Sunnyside became a student- 
dominant community, and fell into a state of decay from decades of minimal maintenance and heavy use. Sunnyside's residential housing capacity was rapidly exceeded, and students were forced to seek other rental housing options across and outside of Morgantown. Beyond the city limits, large scale apartment complexes were built in the early 2000s due to cheaper land prices. These new complexes have placed a considerable load on the small density roads around and in Morgantown, creating traffic congestion and strain on the transportation system. The urban transformation that Morgantown is currently undergoing demonstrates a critical need for Immersive GeoDesign to visualize and plan for these changes effectively.

\section{Data Assembly and Ingestion}

Spatial data for this research was obtained through the WVGISTC, the City of Morgantown, WV, and Google 3D Warehouse. The data consisted of 2D building footprints for Morgantown; two-foot contour DEM; three-foot resolution NAIP imagery; maximum building heights for different land uses; and several individual building models were obtained from SketchUp 3D Warehouse or were personally generated using SketchUp. This data was combined within CityEngine to create a virtual geosimilar representation of the city of Morgantown, WV.

Several stages were involved in constructing the 3D models. The building footprints were combined with the land-cover map of Morgantown (Figure 4-1) (http://www.morgantownwv.gov/wp-content/uploads/official_zoning_map_07-01-2012.pdf). Maximum building heights were assigned to the building footprints. Data processing was performed in ArcGIS Editor by adding attribute fields, populating these fields with a Morgantown land use code and maximum building height, and then exporting the shapefile into CityEngine. Prior to importing the building footprints into CityEngine, the terrain was created 
by importing the DEM (known in CityEngine as a height map) and NAIP imagery to achieve a georealistic terrain and land cover for Morgantown. The building footprints were then imported into CityEngine and draped over the terrain. At this juncture, the models consisted of 2D footprints on a terrain model that was ready for the buildings to be procedurally generated within CityEngine.

\section{Custom SketchUp Model Importation}

Prior to procedurally modeling the built environment in CityEngine, landmark buildings, which largely comprised the historic WVU Downtown Campus, were created within SketchUp or downloaded from 3D Warehouse and exported as KMZ (a Google Earth extension) models directly into CityEngine. Once the custom models were imported in CityEngine, they were manually located and oriented. It is worth noting that CityEngine procedural rules allow for the placement of KMZ models, but due to the relatively small number of custom buildings in this project, the manual placement proved to be a faster alternative to place and orientate each individual model. The procedural placement of KMZ models worked much better for locating street furniture, shrubbery, trees, and other smaller miscellaneous objects in the landscape (Figure 4-2).

\section{Procedurally-Generated Buildings}

The procedural rules for extruding and rendering the $2 \mathrm{D}$ building footprints into $3 \mathrm{D}$ building models were developed for the different vignettes of the case study. The first procedural ruleset was written to create a geosimilar built environment of Morgantown. The land use and maximum building height attributes of the $2 \mathrm{D}$ building footprints were obtained at the start of the procedural ruleset and were set as attributes that determined the heights of 
buildings and how the buildings should be rendered. The procedural ruleset was written using "case" statements specifying the land use code within the 2D building footprint attribute table.

To generate models with differing heights, each land use attribute instructed CityEngine to extrude a building footprint to a randomized height no greater than the maximum height attribute. A rendering "component" for each face of the newly extruded model was then created. This component feature enabled individual rules for each face of the building and the roof to be rendered based on the land use attribute. Once the ruleset was completed, it was applied to all building footprints and the built environment was generated and displayed (Figure 4-3). The second procedural ruleset created a 3D thematic map of the five main land uses found in downtown Morgantown (Figure 4-4). Figure 4-5 illustrates the 3D land use procedural rule as applied to Greater Morgantown. The procedural rule for parking was automatically applied to a selected building model to illustrate occupant needs for parking.

\section{$\underline{\text { Ingestion into the CAVE }}$}

Once the procedural rules were created and applied in CityEngine and within the CAVE, the scene was then ingested into ArcGIS. Using the entire built environment of Morgantown within ESRI's ArcScene is not feasible because of the caching issue. However, for the individual vignettes of the case study, smaller sections of the overall Morgantown scene were created to avoid caching issues and to enable optimal interaction within the CAVE. In the following sections the programming and procedures involved in pursuing each of the four vignettes are detailed and the results are reported in Chapter 5. 


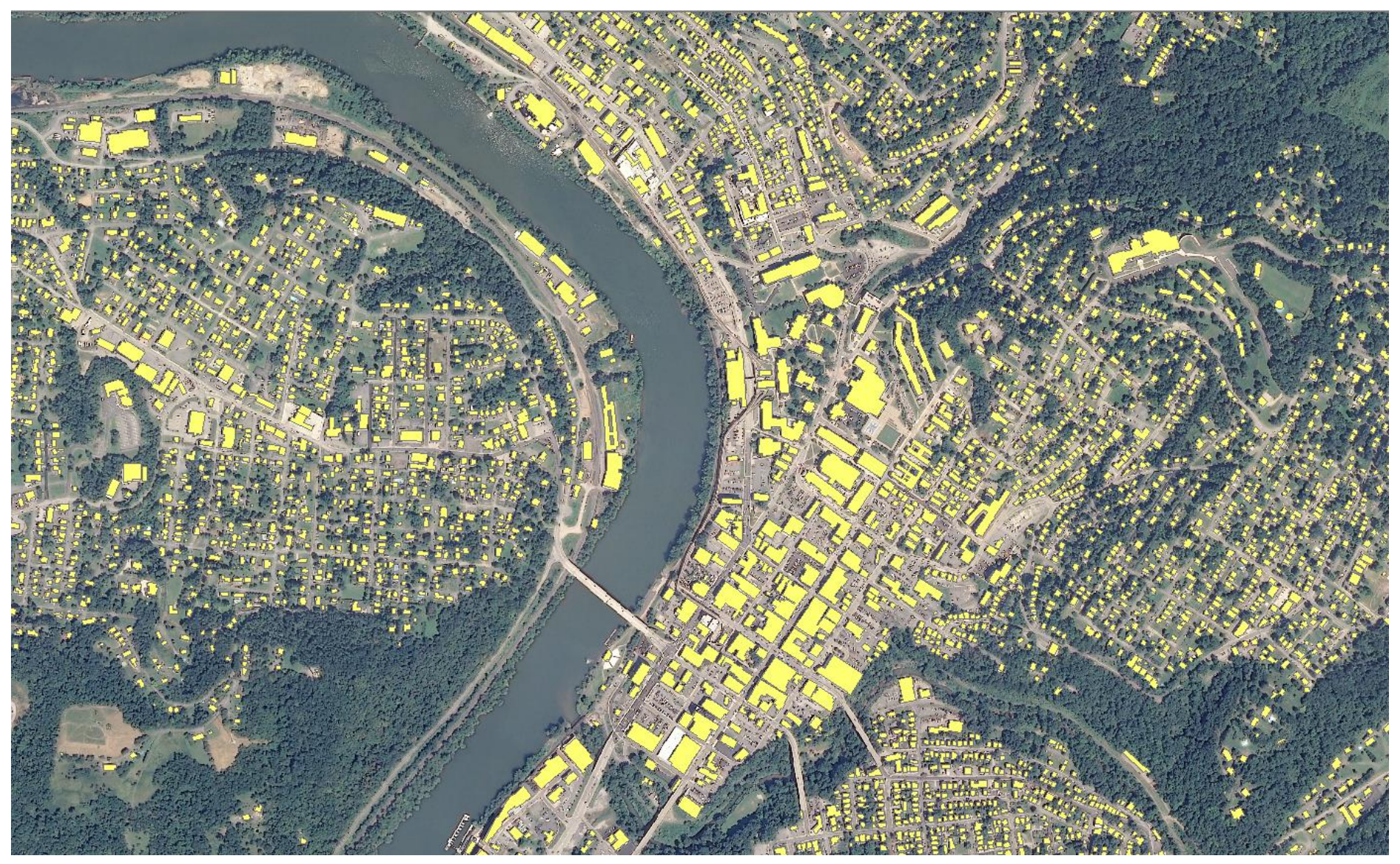

Figure 4-1: City of Morgantown 2D building footprint shapefile draped over three-foot NAIP imagery within ArcGIS. The shapefile attributes included land use and maximum building height, both of which were identified and used within the procedural rules of CityEngine for extruding and rendering the built environment. 


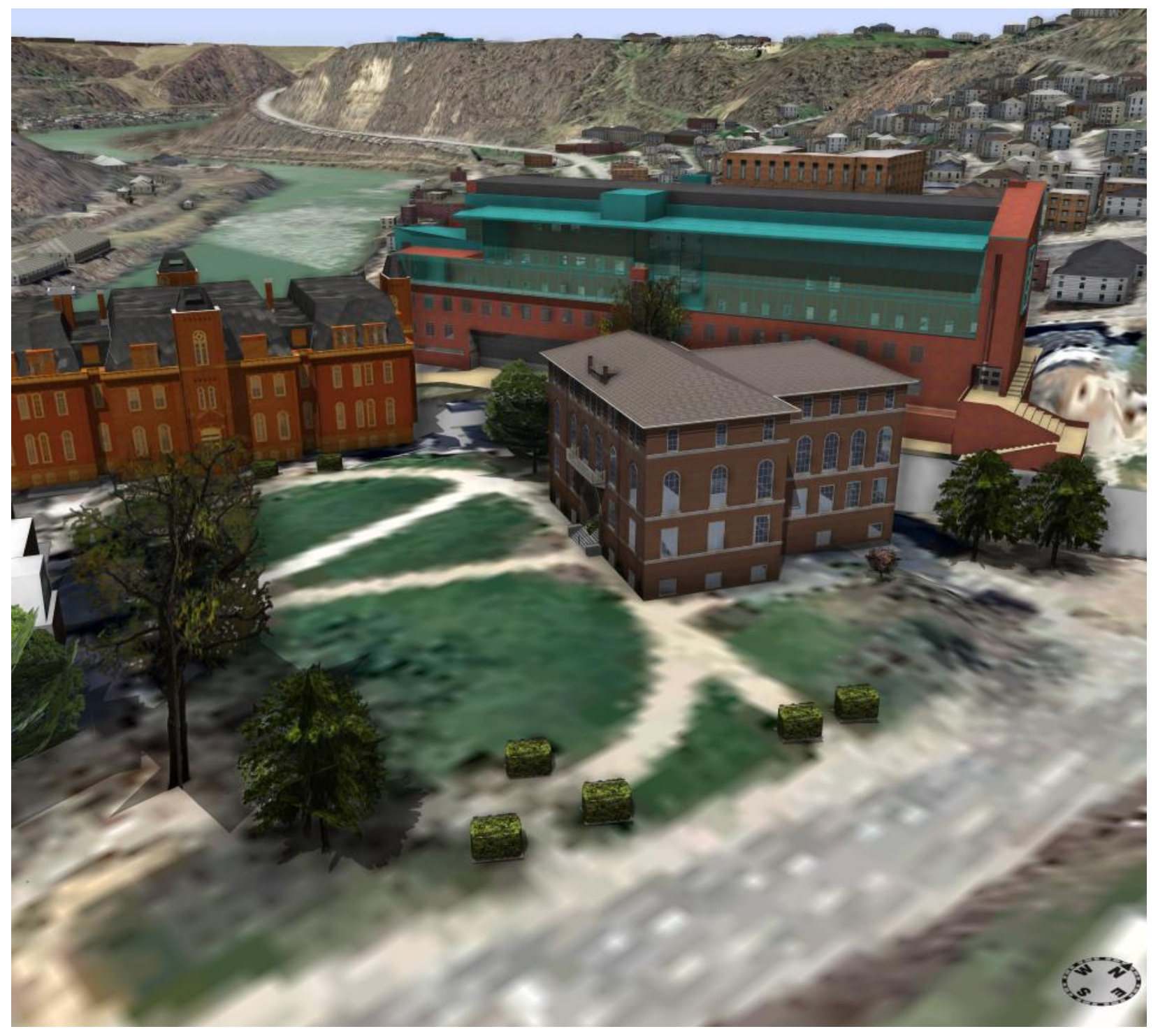

Figure 4-2: SketchUp models used within CityEngine to create WVU's historic Woodburn Circle, with Sunnyside, the Monongahela River, and Evansdale in the background. The building models were placed manually on the terrain due to their individual orientations and small number. Street furniture and vegetation were located through procedural rules due to their larger quantity and lesser need for high detail. The buildings in Sunnyside are mostly procedurally generated as houses or apartment buildings. 


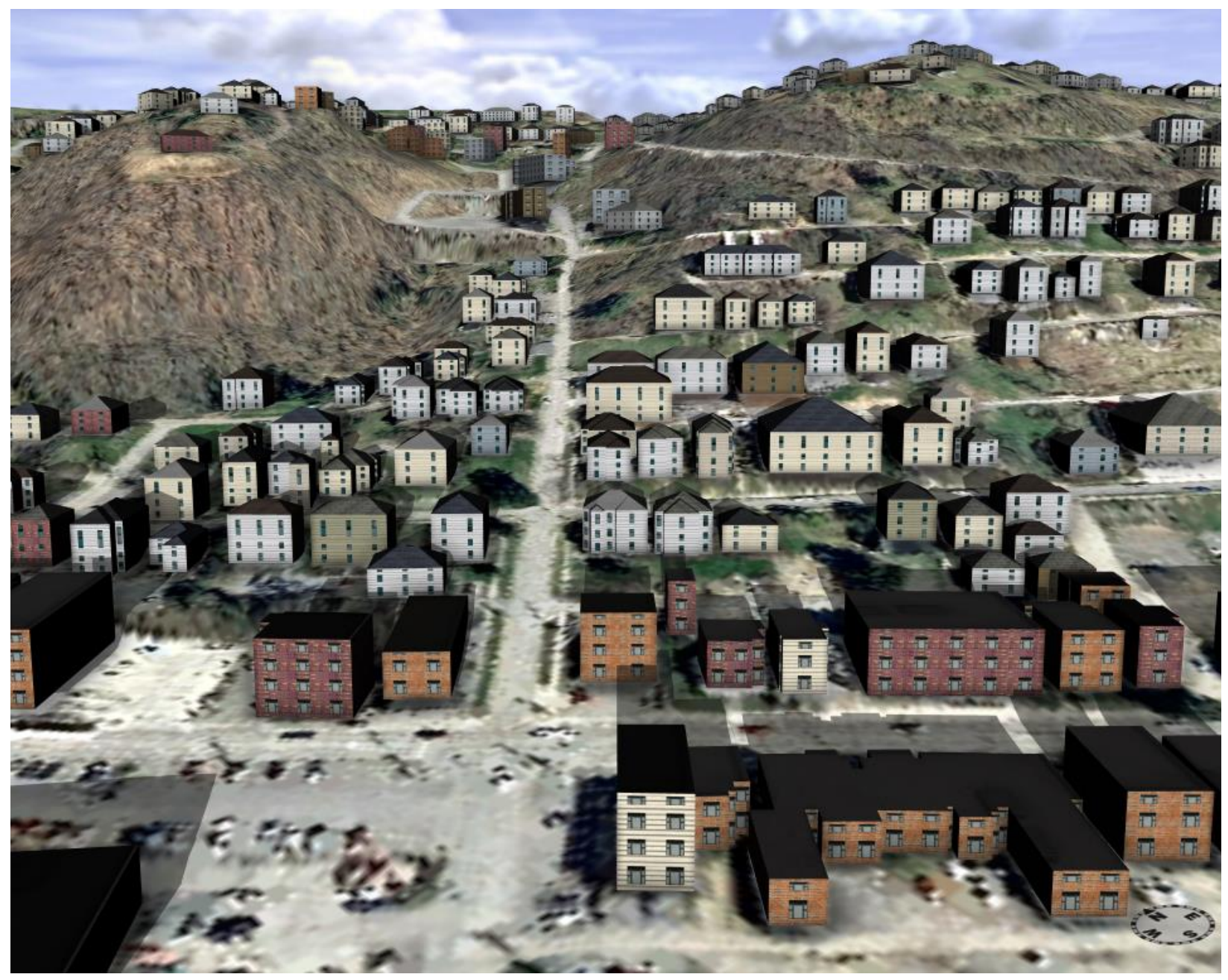

Figure 4-3: The procedurally-generated built environment of the Sunnyside neighborhood in Morgantown, WV. Two different building types can be seen here reflecting different land uses. Residential land uses were procedurally generated as houses with randomized wall textures and sloped roofs. Professional and business buildings were procedurally generated with randomized brick textures and flat roofs. Windows and doors were also placed procedurally on the building facades.

Vignette 1: Vertical Land Use Differentiation

The first vignette of the Morgantown Immersive GeoDesign case study was to examine land use by floor within a combined professional, residential, office (PRO) zoned area. PRO uses are usually displayed in 2D maps, for there exists no inherent way to display the different uses of each floor in traditional GIS. Procedural rules were used here to visualize the different uses of each building floor for a PRO development in Downtown Morgantown. The LandUse 
case statements within the procedural rules of the initial rendered environment were altered to create rules for thematic coloring schemes to be applied based on floor use (Figure 4-4). The thematic mapping procedural rules determined the color functions based on the desired color symbology for each particular land use (Figure 4-5).

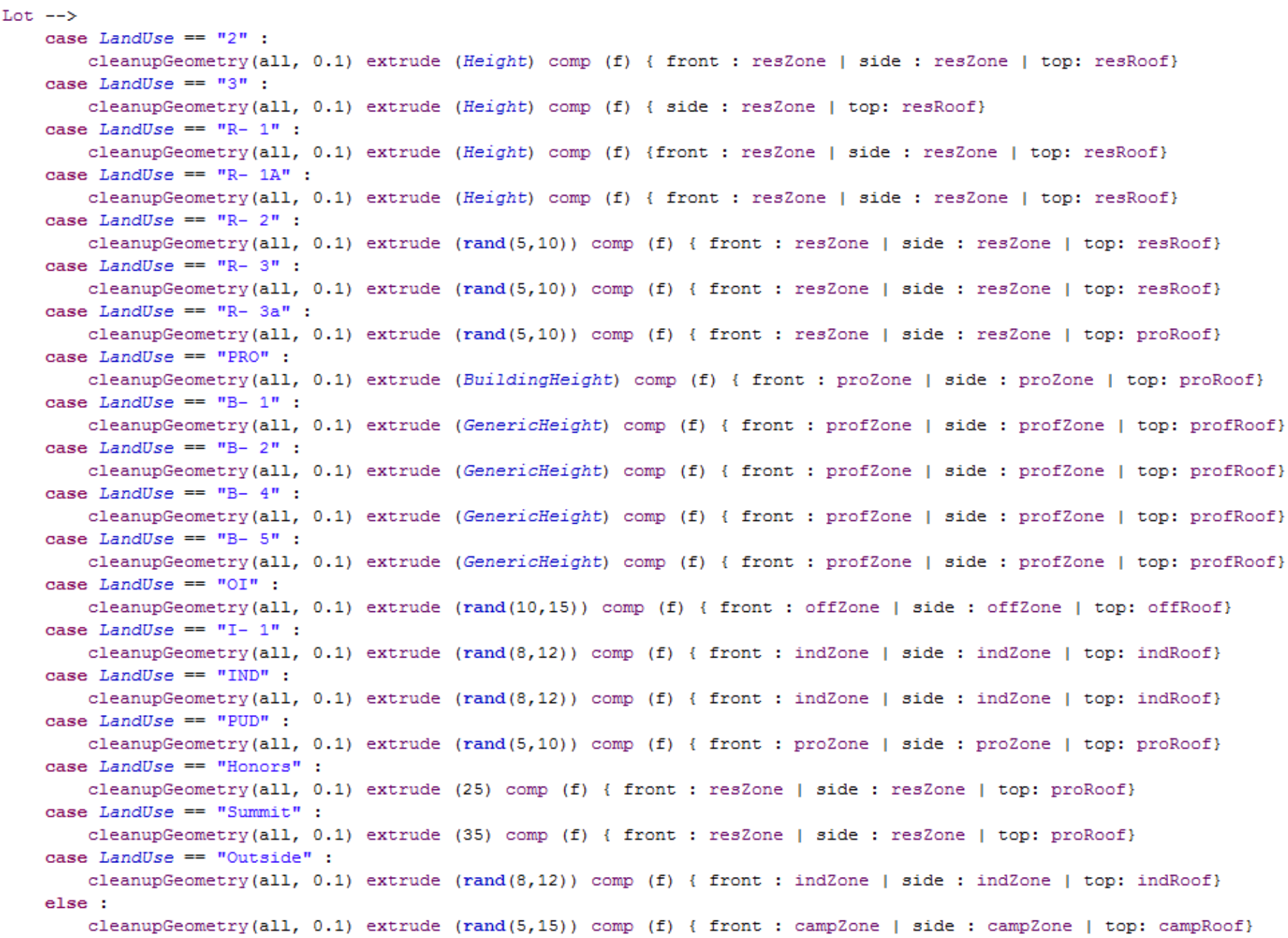

Figure 4-4: Procedural rule snippet for the vertical land use vignette of the case study. While set up in the same format as Figure 3-2, the distinction here is that land use has been generalized to five main categories: residential, professional, PRO (professional, residential, office), industrial, and WVU/educational/other. As CityEngine cycles through the case statements and identifies the land use of each $2 D$ building footprint, the proceeding sub-rules render the buildings into a $3 D$ thematic map based on the five use categories. 


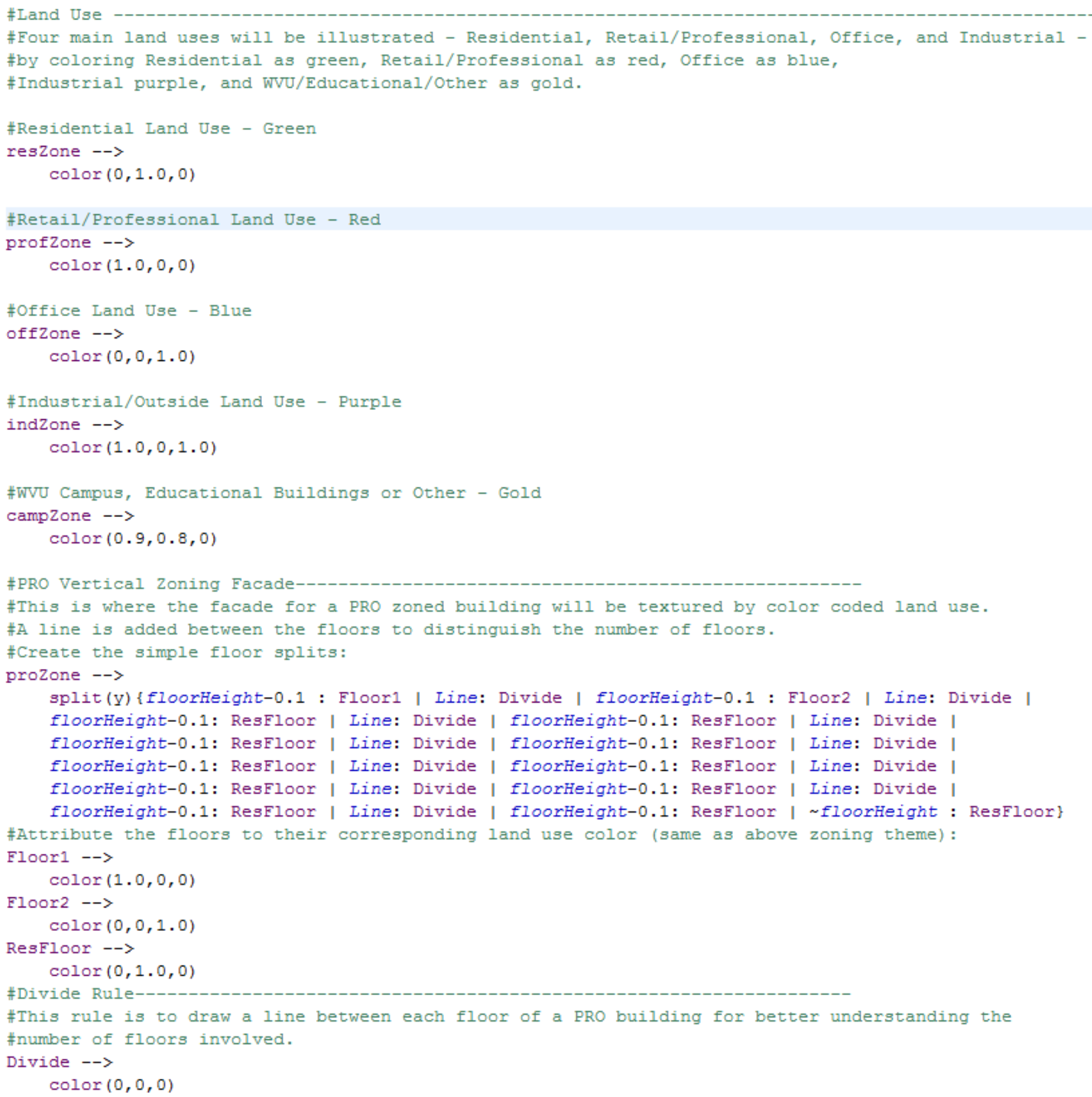

Figure 4-5: Procedural rules for indicating the symbology to be applied to buildings with differing vertical land use. 


\section{Vignette 2: Parking}

New developments in downtown Morgantown must accommodate off-street parking for residents and professional clientele. Due to the limited space of the downtown area, at-level parking lots are not a practical option, and new developments must invariably utilize parking structures in the basement levels of buildings in order to optimize use of space. The requirement for parking space is usually based on a function related to the number of occupants in the building. Here, CityEngine is used to demonstrate how the procedural rules can assist in automatically calculating the space and number of floors required for parking based on building size and occupancy, and to update the model in real-time as changes to the building design occur. These automatic procedures are valuable in relieving decision makers of manually calculating the car space requirement and especially so when contemplating building design changes.

To this end, a building that had been proposed for construction was partitioned into floors. Since new Downtown developments are generally of mixed land uses, the proposed development was illustrated as a PRO land use, with the same symbology (professional - red, office - blue, residential - green) but including a new symbol added for parking (white). First, the building was extruded by the BuildingHeight attribute in CityEngine, which is a product of the number of floors (Floors attribute in Figure 4-6) multiplied by the height of the floors which was set to 3.5 meters. Case statements were used to determine the number of floors of basement level parking required based on the gross square foot (GSF) area of the building. In Figures 4-6 and 4-7, the GSF area of a building was used to determine whether the building required one or two floors of basement level parking. More than two levels of basement parking would prevent street level access to storefronts on either side of the building. Depending on the BuildingHeight attribute, the BuildingGSF attribute (initially set as 0) was set to randomize between the 
calculated values of area for each floor. The values for GSF were set to be the GSF for floors one to six, and for seven to twelve (the maximum height of the building cannot exceed twelve floors for this example, per the Morgantown Building Code).

Once the GSF was established based on the case statements, another set of case statements were used to determine the number of floors of parking required for the building. If the GSF was below or exceeded the values in Figure 4-7, the case statement removed or added a floor of parking to the building's 3D thematic map. To visualize the $3 \mathrm{D}$ thematic map, a Height attribute (set to 3.5 meters as the floor height), a Line attribute (set to 0.1 meters as simply a divider between floors), and the procedural rules for setting color values for each use were utilized. To summarize, if the building should exceed six floors, theoretically the GSF crosses the threshold and two floors of basement level parking were then required for the building development which CityEngine then displayed. 


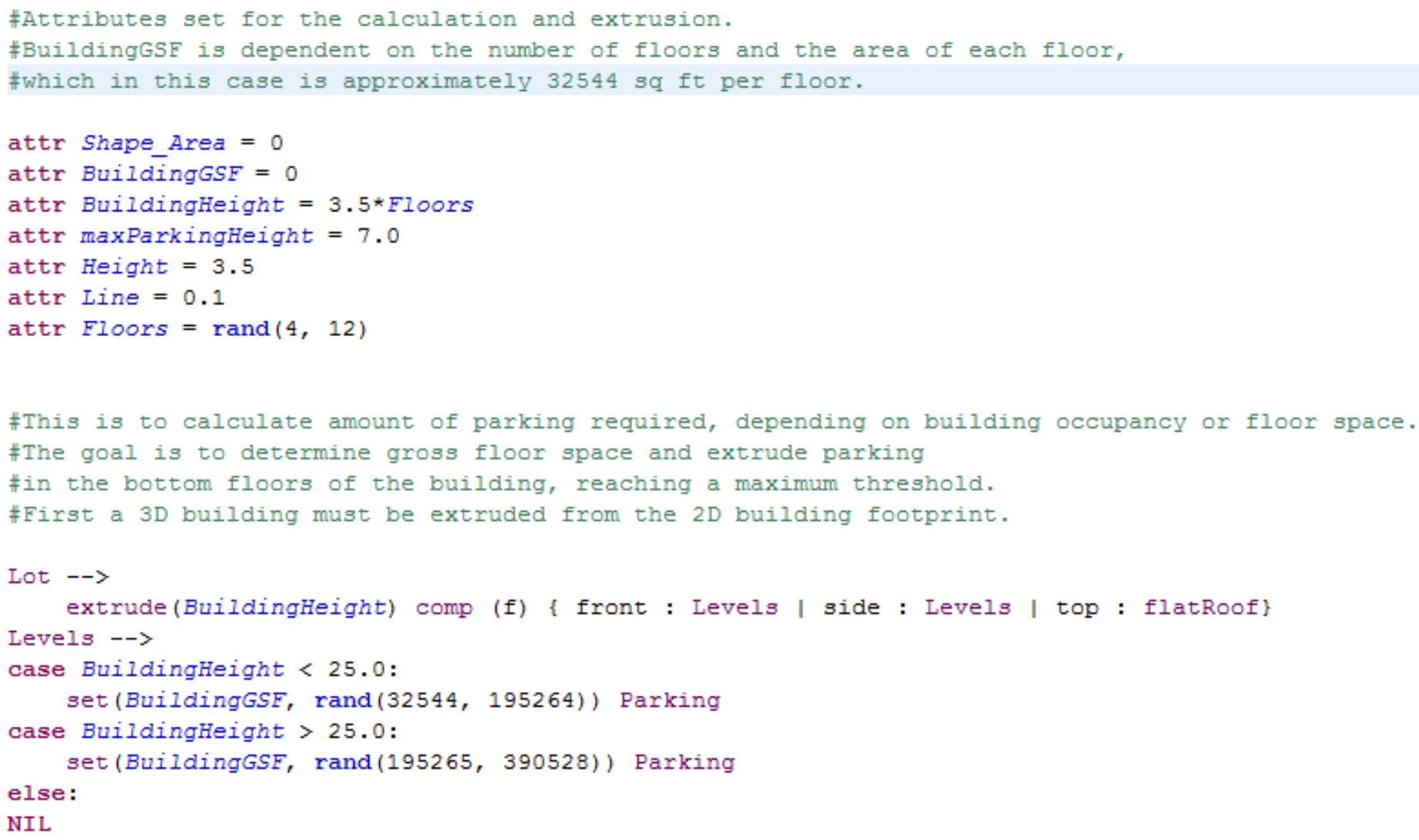

Figure 4-6: Procedural rule script for the parking calculation and visualization, showing attributes and case statements for gross square foot $(G S F)$ values for the visualization. 


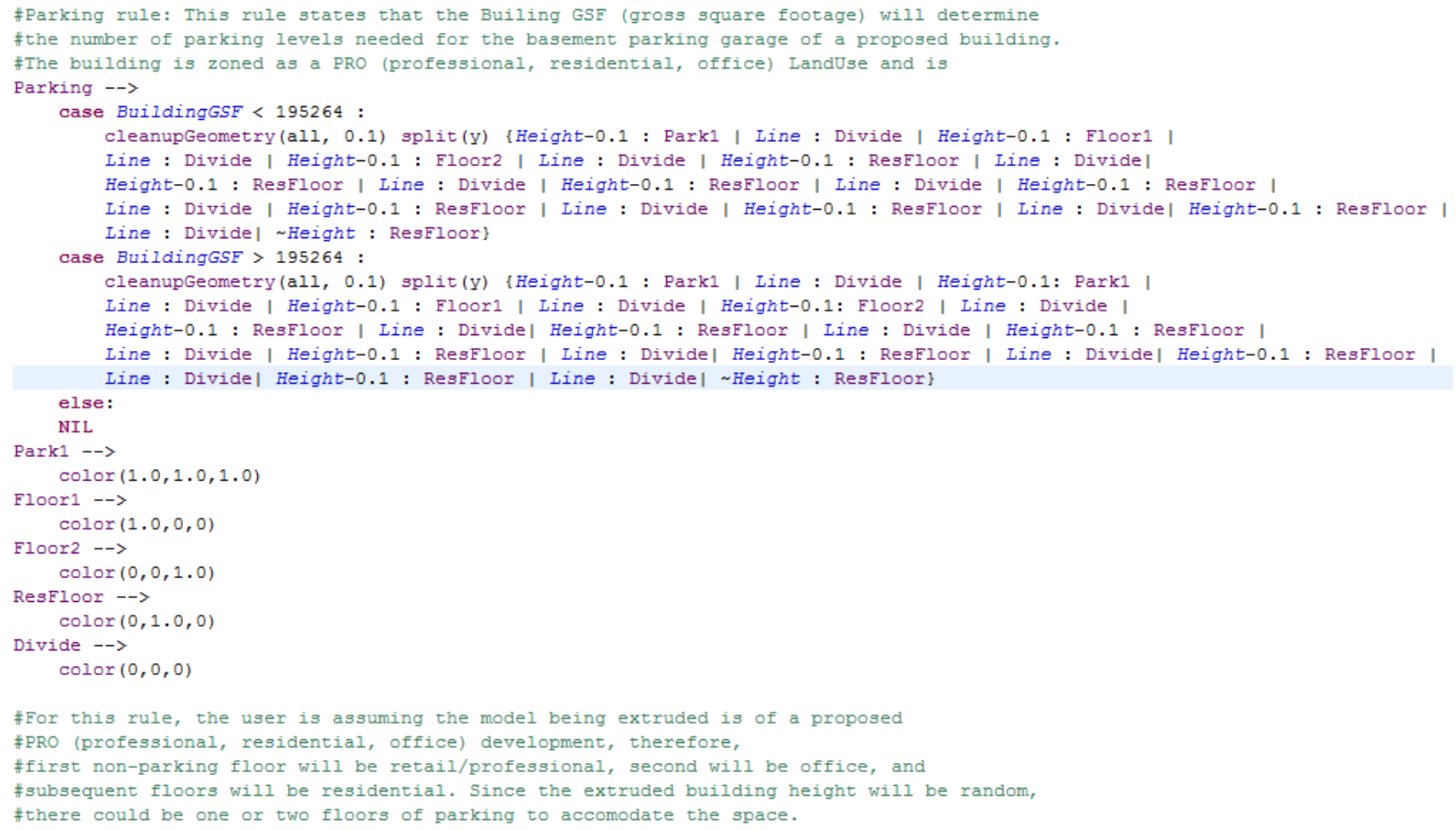

Figure 4-7: Procedural rule script for the parking calculation and visualization, illustrating the case statements for how each floor is visualized with the basement level parking.

Vignette 3: Sun Shadow Analysis

A third vignette was to identify possible light capture limitations arising from shadows cast by adjacent high-rise buildings. Identifying light capture is critical in right-to-light issues and employing possible solar panel installations or energy efficient window fixtures. The area selected for this vignette was High Street in Downtown Morgantown and for a new proposed structure on Don Knotts Boulevard, as it possesses a number of tall buildings in close proximity to other buildings. ArcGIS's 3D Analyst toolbox possesses the Sun Shadow Volume tool (shown in Figures 4-8 and 4-9), which produces a 3D polygon depicting the sun shadow for any given date and time. 
Due to the stark differences in the sun angle between the two solstices, both summer and winter solstices were input as dates for the Sun Shadow Volume tool, with the time set to 12pm Eastern Standard Time, respectively. In both Figures 4-8 and 4-9, the High Street Building models had to be split into west and east side groups to accommodate what can only be classified as an error in the Sun Shadow Volume tool that would not produce proper sun shadow volumes for all the intended buildings of High Street. The procedure produced the sun shadow volumes for each of these separate groups of buildings. The tool possesses an option to iteratively run the Sun Shadow Volume tool for minutes, hours, or days until an end date and time, but by using the dates of the solstices, obtaining sun shadow volumes in between those dates was unnecessary. The resulting sun shadow volumes were initially symbolized as solid white 3D polygons, which proved unhelpful to interpretation and thus a $45 \%$ transparent black symbology was used for rendering pseudo-realistic but interpretable shadows. 


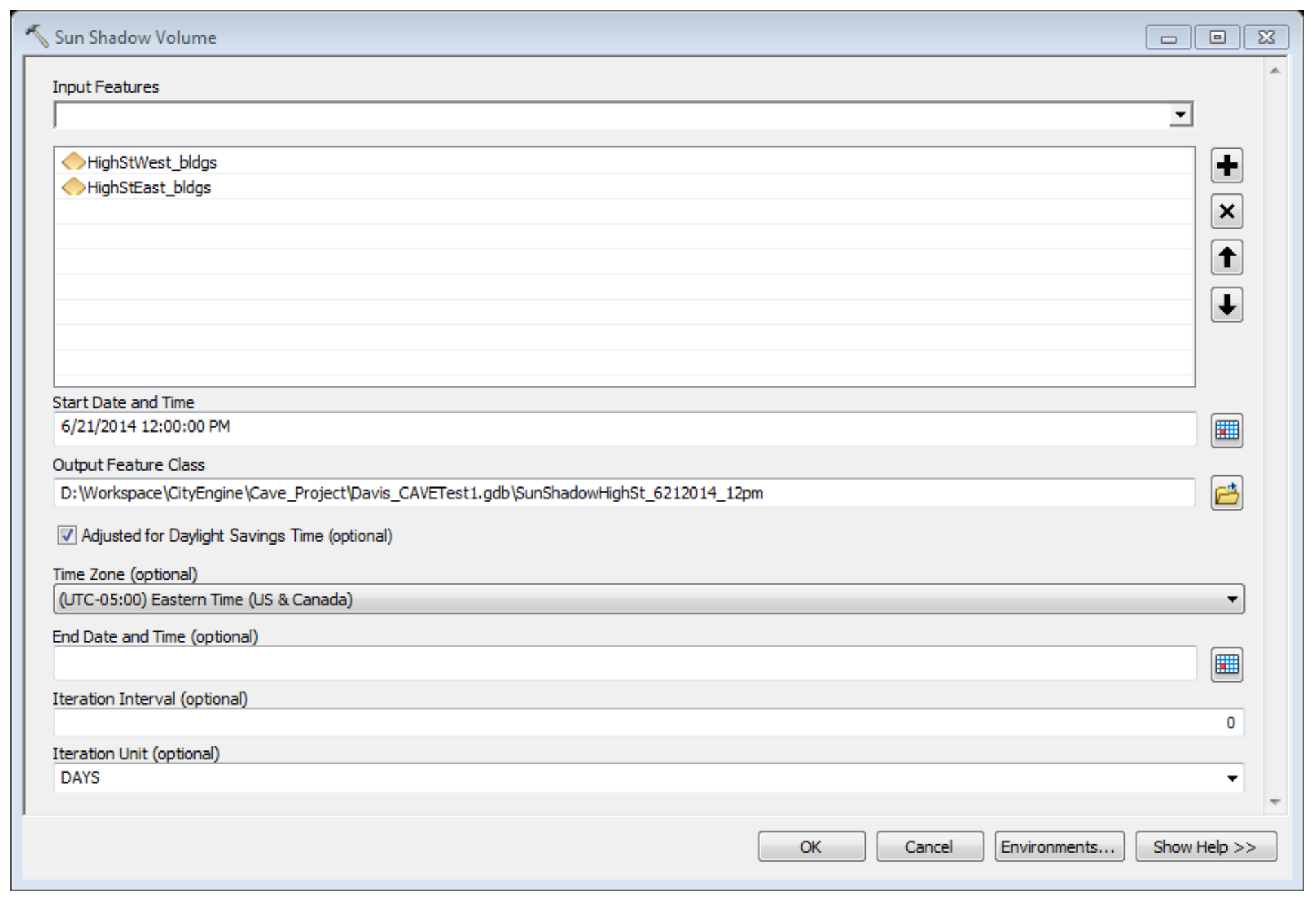

Figure 4-8: Sun shadow analysis of downtown High Street buildings at the summer solstice (6/21/2014) at 12pm EST. 


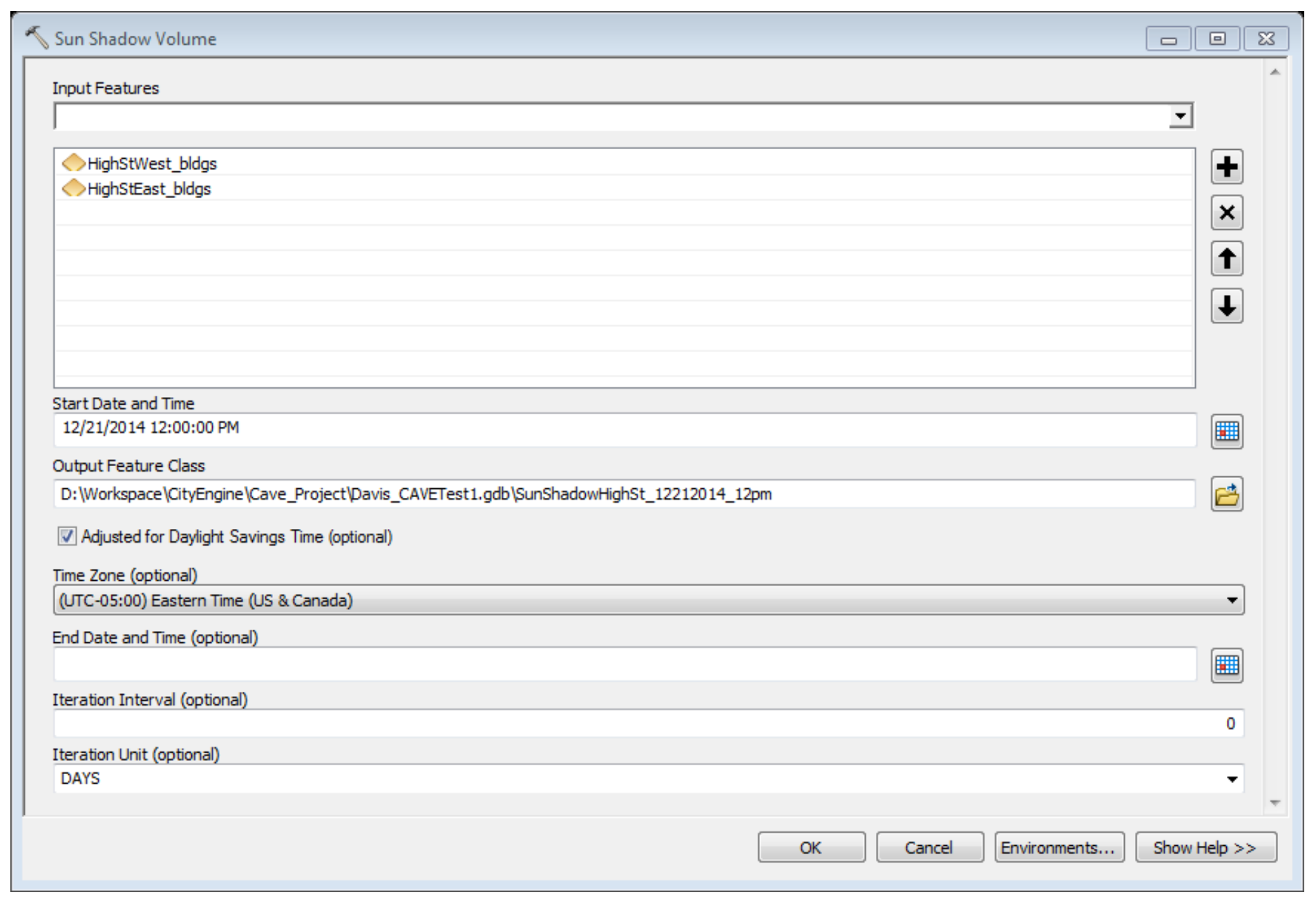

Figure 4-9: Sun shadow analysis of downtown High Street buildings at the winter solstice (12/21/2014) at 12pm EST.

Vignette 4: Intervisibility Analysis

The final vignette of the case study addressed the issue of intervisibility in the built environment. Intervisibility is essentially a case of determining the line-of-sight between specified locations but taking into account potential intervening obstructions (http://resources.arcgis.com/en/help/main/10.2/index.html\#//00q9000000nn000000). The Intervisibility tool within ArcToolbox creates a binary "visible" attribute of user-created sight lines to indicate if the sight line is obstructed by selected 3D features, whether terrain surfaces or 
building models. Observer points were established from which to derive the sight lines needed for the intervisibility analysis. Using 3D Editor within ArcScene for a 3D point feature class, eight points were placed around the downtown area of Morgantown and on the WVU campus to examine intervisibility between nearby locations and landmarks further away (Figure 4-10). The ArcToolbox tool "Construct Sight Lines" generated the sight lines from each of these observer points (Figure 4-11). Since the tool used a 3D point feature class, the sight lines accommodated 3D buildings and other obstructions. The need for 3D GIS in Immersive GeoDesign is clearly demonstrated here for it is challenging indeed to meaningfully perform this task in a 2D GIS environment devoid of buildings or other various potential obstructions.

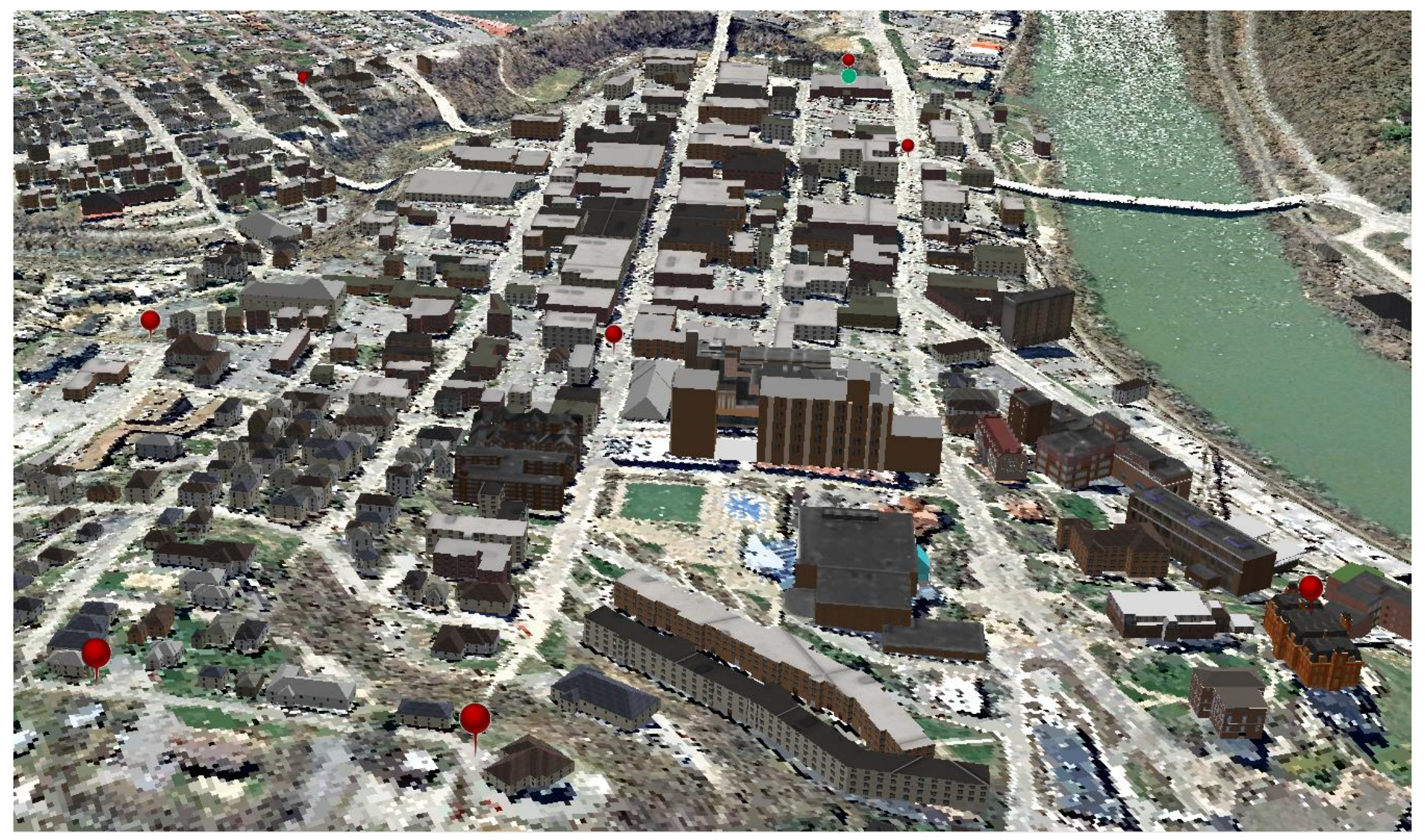

Figure 4-10: Observer points (red pins) placed for the sight line creation phase of intervisibility analysis. 


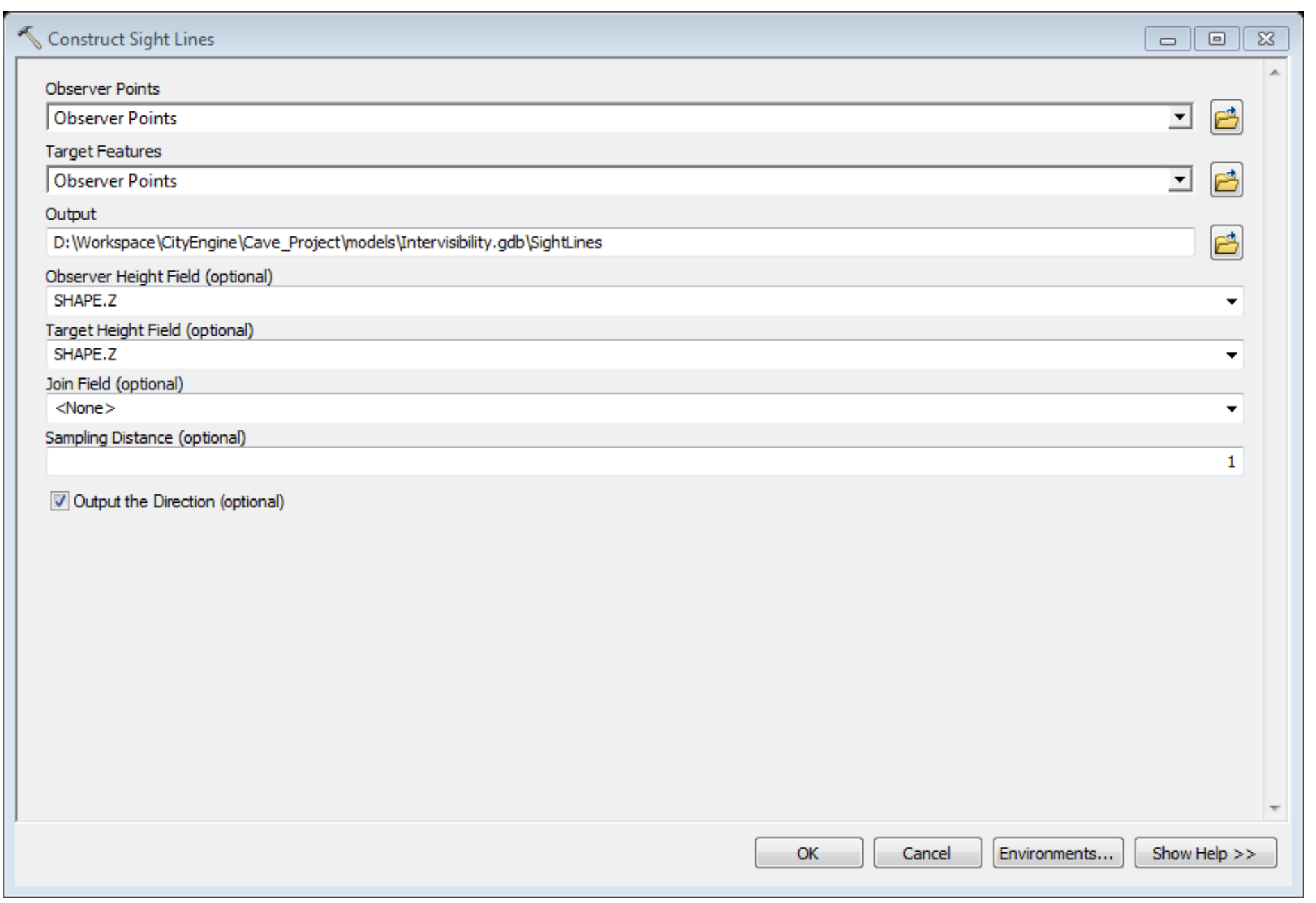

Figure 4-11: Constructing sight lines using the observer points shown in Figure 4-10.

Once the sight lines were created, the intervisibility tool (Figure 4-12) created a new field "VISIBLE_Procedural" in the sight lines attribute table, using the procedurally-generated downtown buildings layer. The resulting values of " 1 " or " 0 " indicate "visible" or "not visible," respectively. The sight lines were then symbolized green for "visible" and red for "not visible," based on the attribute field, allowing for visual analytics within the CAVE to determine how visible a new building would be from WVU's Downtown Campus or Downtown Morgantown. For evaluation purposes, a traditional visibility analysis was performed on the Morgantown scene, using the same observer points, and the intervisibility results were compared. 


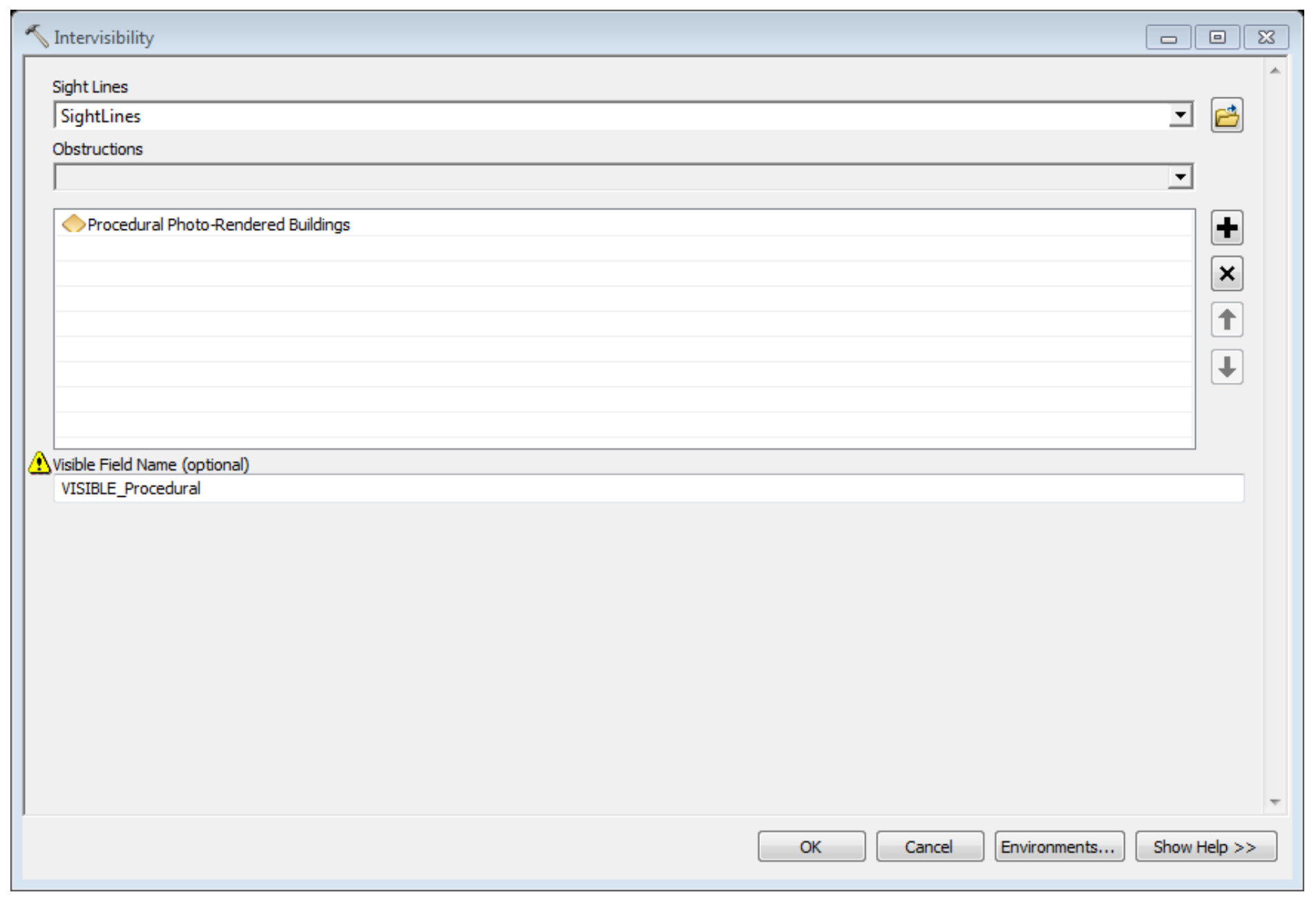

Figure 4-12: Intervisibility tool run for the proposed development. The tool is run for the procedurally-generated Downtown buildings layer to illustrate the intervisibility of the proposed development and surrounding areas. 


\section{Chapter 5: Results of the Immersive GeoDesign Case Study}

The first vignette of the Immersive GeoDesign case study focused on the vertical visualization of land use by floor in mixed use buildings. CityEngine Procedural rules were used to render the use of each particular floor of a Professional, Residential, and Office (PRO) development along with the individual land uses of "Professional", "Residential," "Office," "Industrial," and "WVU/Educational/Other" (as shown in Figures 5-1 and 5-2). The choice of five categories within the land use symbolization achieved a "best fit" classification given the land use zoning in the study area of Downtown Morgantown. Residential structures were symbolized in green with angled roofs; retail or professional uses were symbolized in red with flat roofs; office use in blue with flat roofs; industrial use buildings in purple with flat roofs; and WVU, educational, or other use buildings were symbolized with a gold color and flat roofs. Finally, the PRO use structures were rendered, where applicable, with retail or professional use (red) on the ground floor, offices (blue) on the second floor, and the remaining floors were symbolized as residential (green) with black lines dividing each floor.

Figures 5-1 and 5-2 delineate the area of Downtown Morgantown, WV, used for this example. The Morgantown zoning code lists the Downtown area as all general business use (B4), which was reflected in the attributes of the building footprints. However, field verification indicates that most of the structures in the downtown area exemplify the PRO land use designation. A simulated PRO district was created through an alteration of the "LandUse" attribute in CityEngine to generate the PRO symbology along High Street in Downtown. The outcome was a virtual representation where the symbology of mixed land uses was more representative of reality than the city's current zoning map. The 3D models deliberately only 
resemble the structures in shape because the focus is on visual analytics by floor rather than on geosimilarity.

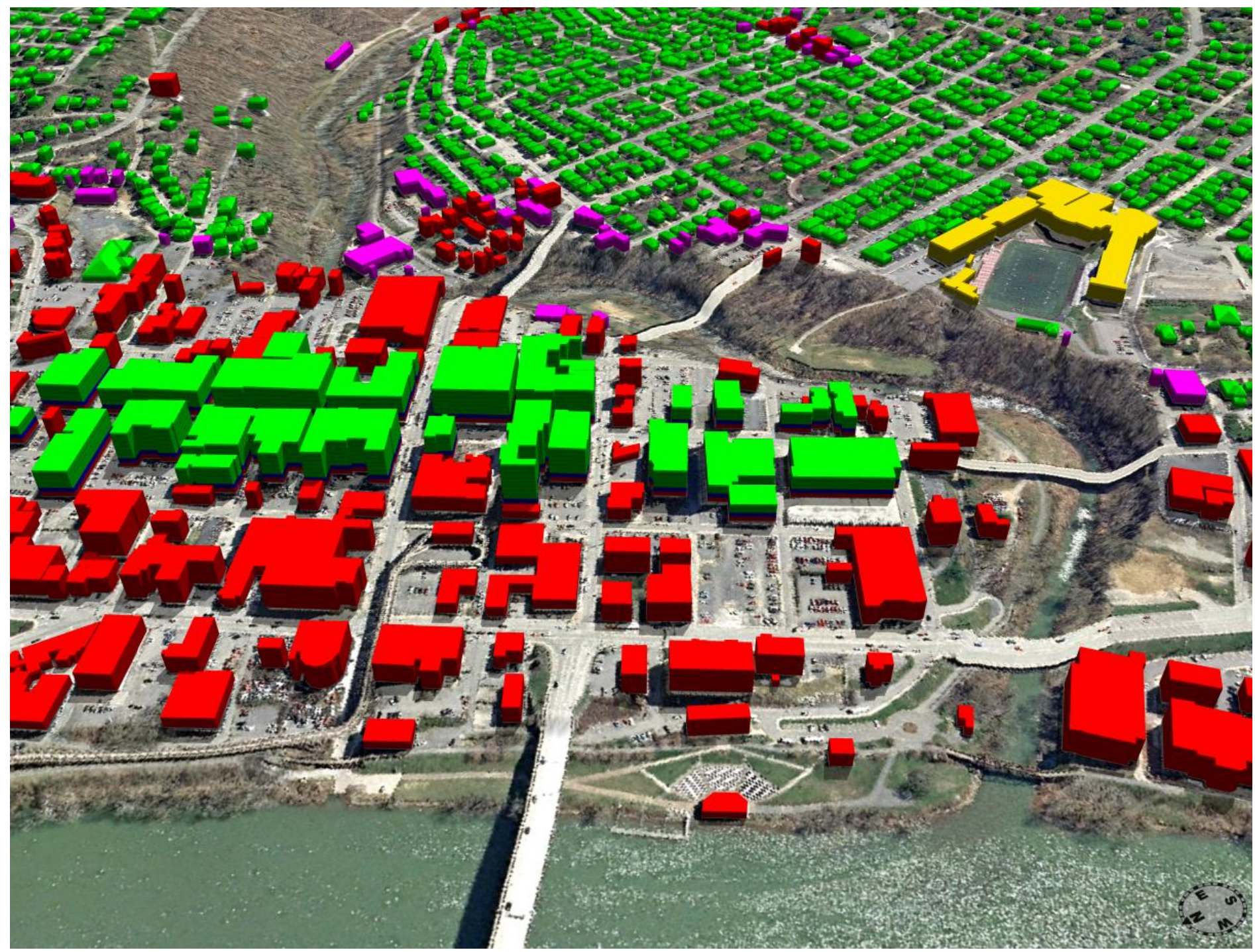

Figure 5-1: A 3D land use geovisualization of Morgantown, WV, created from the procedural rules shown in Figure 4-4. The land uses are identified as residential (green), professional (red), PRO (layered red, blue and green), industrial (purple), and educational/other (gold). 


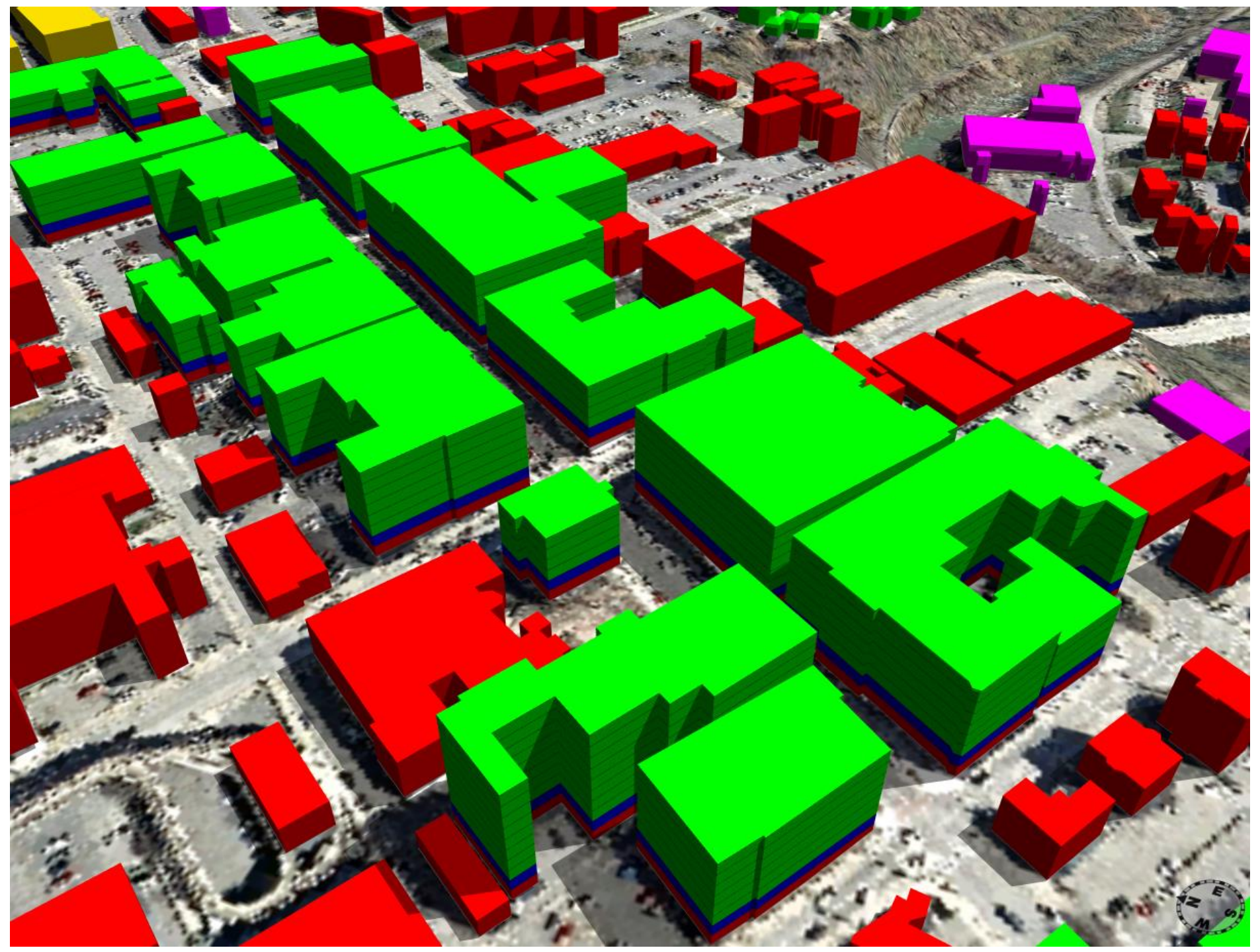

Figure 5-2: A more detailed section of Downtown Morgantown modeled as PRO land use to illustrate the different land use of each floor of the buildings. While 2D mapping can provide a single land use for a particular location, it fails to provide correct illustration of mixed use developments, thereby demonstrating the need for a floor-by-floor, $3 D$ land use rendering.

The second vignette focused on calculating and rendering the appropriate spaces required to be devoted to parking, which is dependent on the total number of floors and occupancy in a building. Case statements sought to identify whether the proposed building required one or two floors of basement-level parking. After the number of required floors of basement-level parking 
was established, the procedural rules then denoted these parking levels as white with black dividing lines (Figures 5-3 and 5-4). Figure 5-3 illustrates the proposed structure's height if built to the maximum allowed height of 120 feet according to planning code (Morgantown Planning Commission). Figure 5-4 offers an additional perspective to view the difference in elevation that would restrict building more than two floors of parking before ground level access to any possible professional and retail storefronts was inhibited.

The procedural rules allow for several building scenarios to be examined whereby with a fewer number of floors, only one floor of basement-level parking is required. However, due to the growth of Morgantown, the increased demand for high-density living and retail space in the downtown area, any current building proposals would realistically be at the maximum height allowed, and maximum parking space would likely be required. It is also worth noting that the procedural rules for the proposed development do not explicitly produce error messages when a building exceeds the maximum height allowed, however a graphical limitation is produced if the user changes the building height beyond that which is allowed. CityEngine stopped rendering the black dividers between floors beyond the maximum allowable height of the building, thereby creating a visual limitation of a distorted top floor. Another limitation within the procedural rule would be that the procedural rule for this model prevented rendering of more than two floors of basement-level parking, since that is the maximum space allowed based on the elevation change of the street levels bordering the building. This approach permits the user to explore multiple design scenarios through changes in the building height attribute in the procedural rules while also staying within the bounds of what is physically possible in the urban site. 


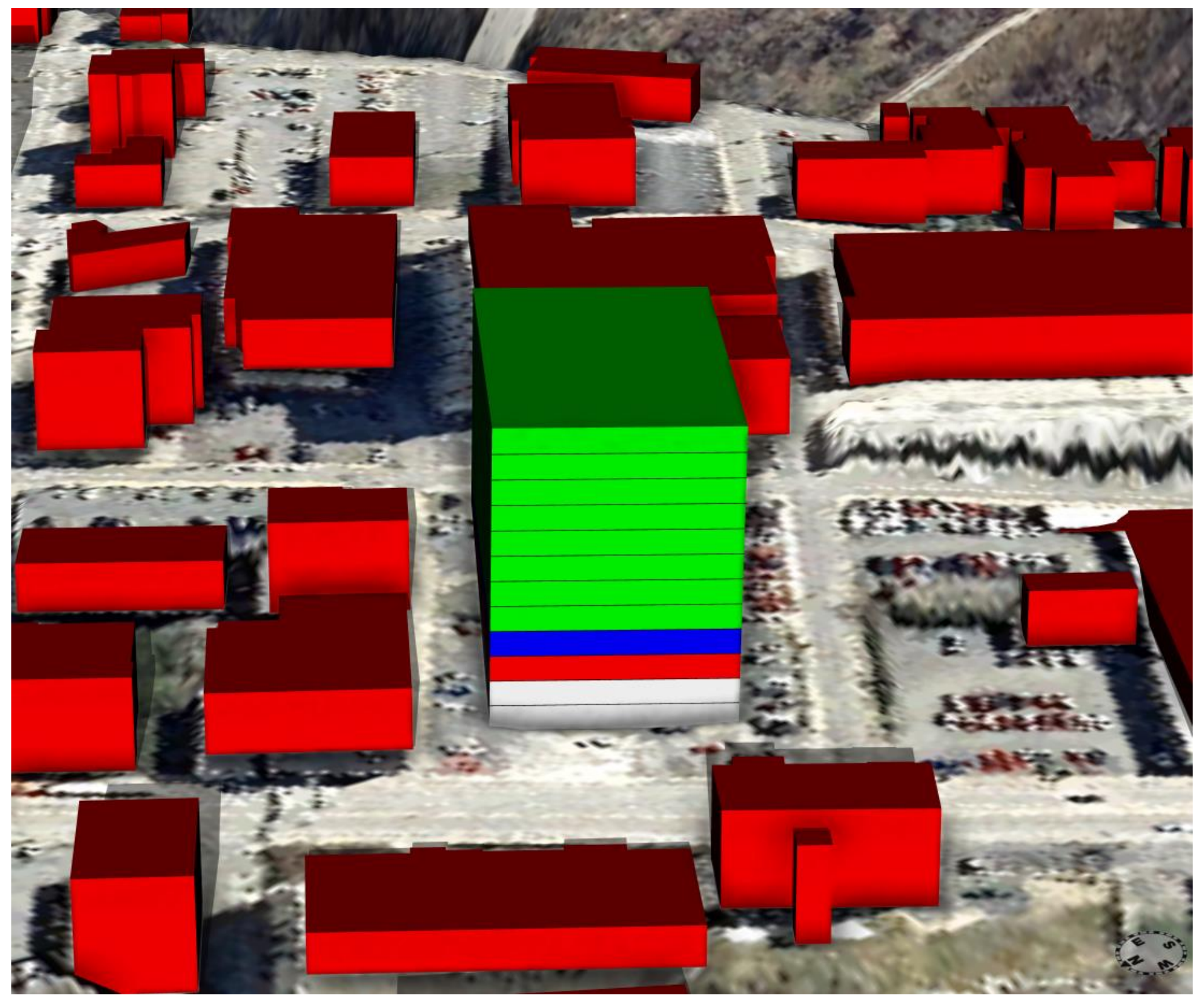

Figure 5-3: Floor-by-floor land use and parking visualization of a proposed structure at a current unused lot in Downtown Morgantown, WV. The scene is rendered the same as a PRO land use, and included is the maximum two levels of parking (white) in the basement level of the building. 


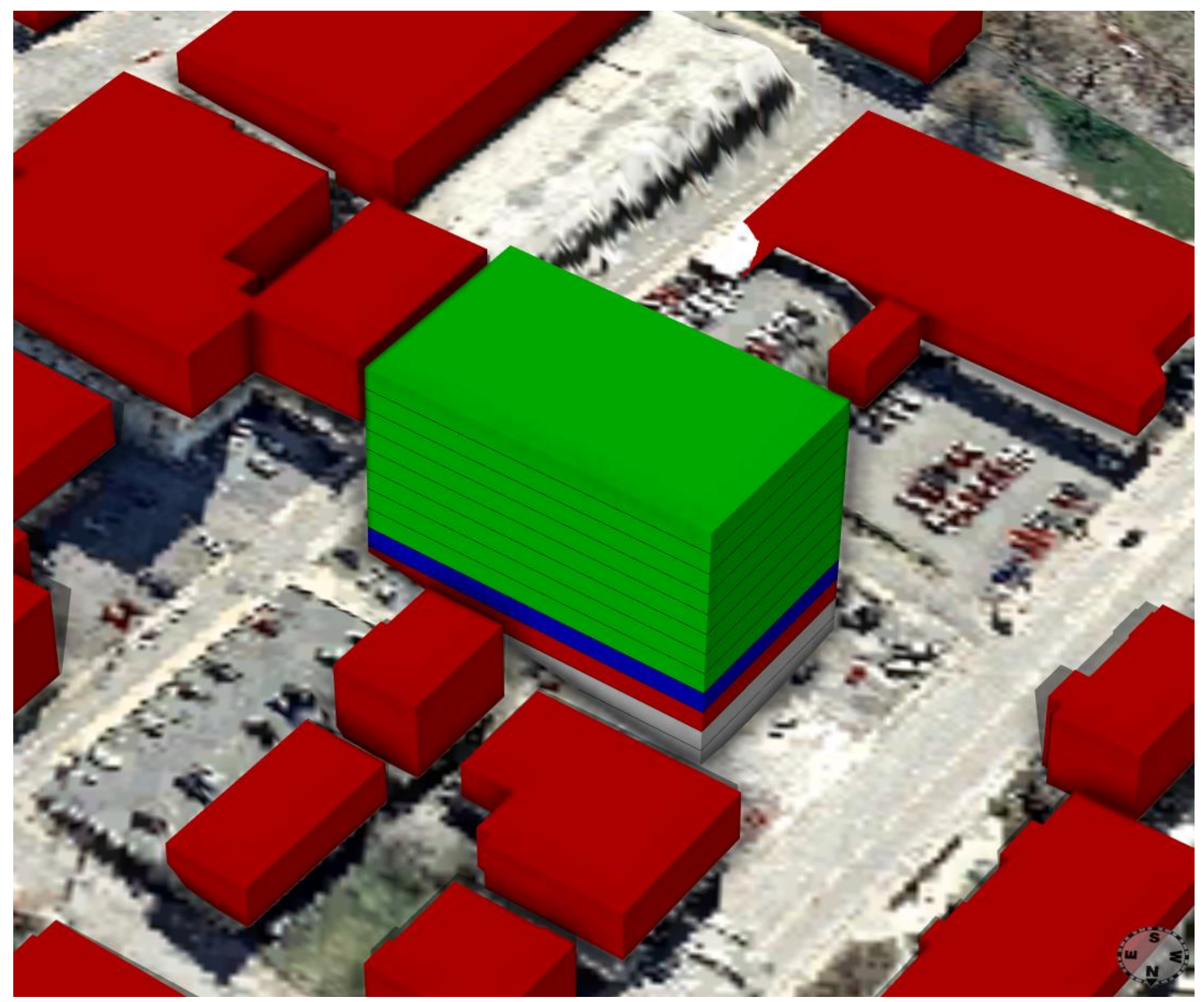

Figure 5-4: Vantage point from the north of floor-by-floor land use and parking visualization. The change in terrain from the northwest side, where parking access would be located, to the southeast side of the building, where storefronts would be located, only allows for a maximum of two levels of basement-level parking since any additional floors will not allow at-level storefront access on any side of the building.

While the first two vignettes of the Immersive GeoDesign case study were centered on a floor-by-floor analysis of buildings, another important component of GeoDesign is that of potential visual and solar light impact assessment. The impact of light capture and shadows 
arising from a new development on neighboring buildings is important to assess, particularly so in the context of light capture. ArcGIS 3D Analyst Toolbox was utilized to perform Sun Shadow Volume analysis for two example areas on the winter and summer solstice (obtained from: http://wwp.greenwichmeantime.com/longest-day/equinox-solstice-2010-2019.htm). The solstices were chosen as they represent the minimum and maximum limits of the sun's position in the sky throughout the year, and provide an effective estimation of shadow on surrounding buildings. The produced sun shadow volumes, based on the color and transparency parameters illustrated in the previous chapter, were selected with an opacity rating such that they ultimately mimicked actual shadow. The High Street buildings demonstrate the effect of the shadows cast on buildings, and also how the collective shadows created areas of permanent or nearly permanent shadow (Figure 5-5). A larger area was considered for the Sun Shadow Volume analysis, but the volumes created for each model created a significant lag in the navigation within the CAVE because of memory issues and lack of ArcScene caching capability, and the buildings along High Street were a compromise in performance while still illustrating the effectiveness of the Sun Shadow Volume analysis on the built environment in Morgantown.

The proposed structure used in the second vignette was included in the Sun Shadow Volume analysis as it provided a valuable example of an impact assessment in Immersive GeoDesign. The dates and times for the analysis of the proposed structure remained unchanged from the High Street buildings example, and the generated shadow volumes produced were given the same color and transparency. The 12:00 pm, June 21, 2014 solstice shows an expected minimal shadow (Figure 5-6), however the 12:00 pm, December 21, 2014 solstice (Figure 5-7) shows a large swath of buildings and land covered in shadow from the proposed building; in fact, the shadow cast completely covers two neighboring buildings entirely and greatly impacts two 
others. The results of the Sun Shadow Volume analysis on the proposed structure concluded that up to four neighboring buildings could very well struggle with light capture issues for a considerable span of the year if the proposed structure were built at its allowable maximum height.

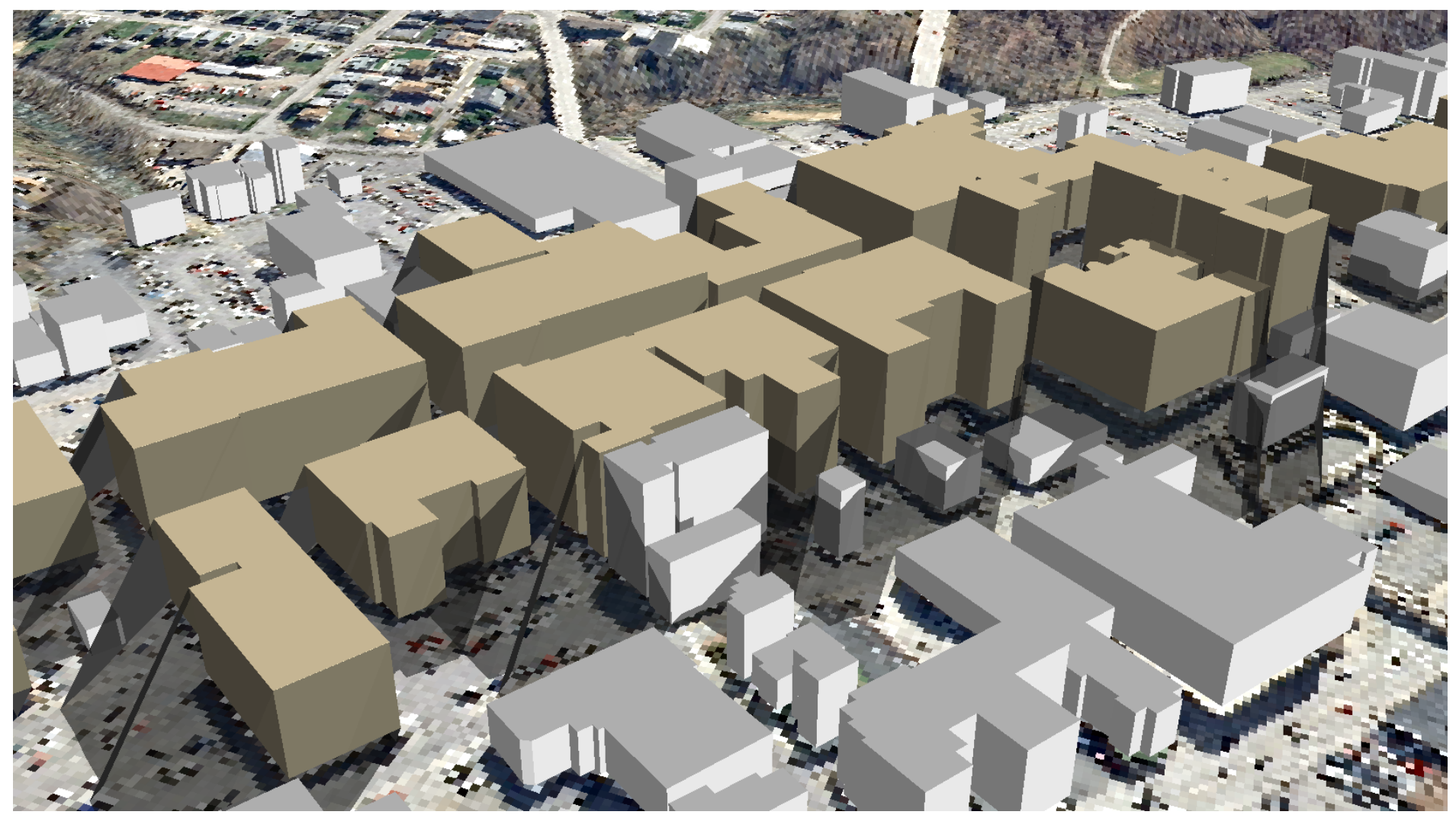

Figure 5-5: Sun shadow analysis of Downtown High Street buildings (in beige). Shadow (45\% transparent black) depicted at winter solstice (12/21/2014) at 12:00 pm EST. 


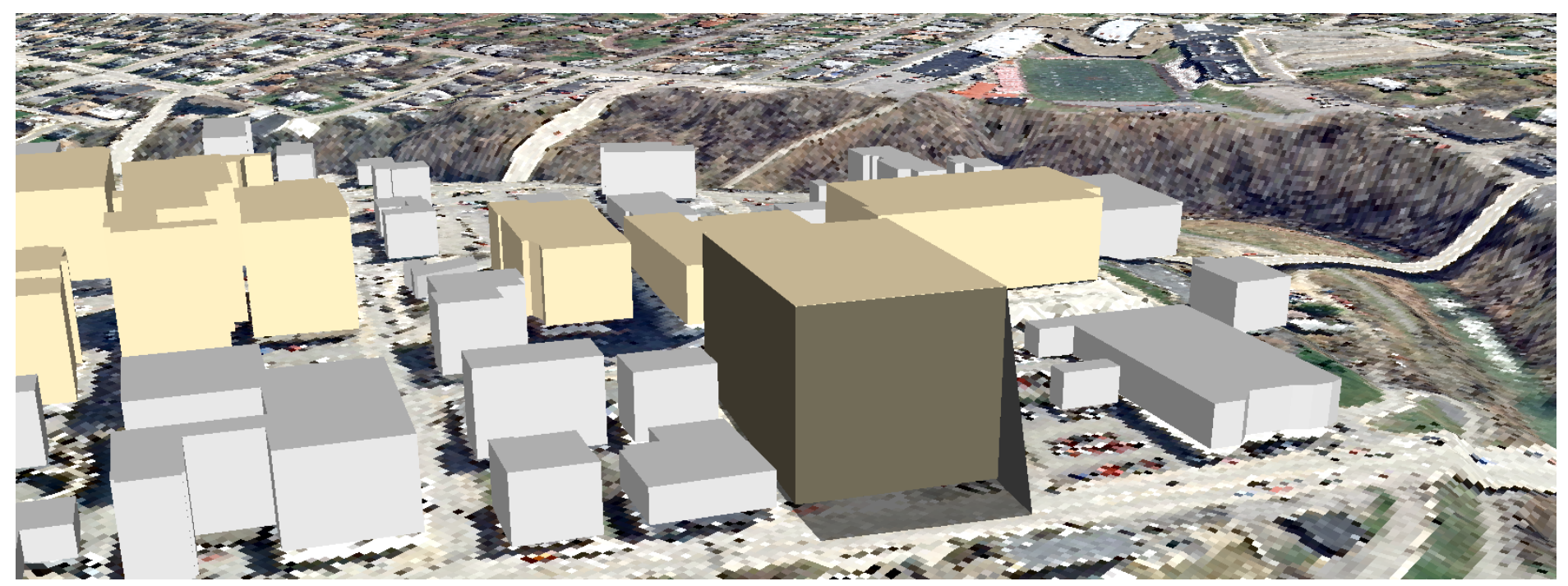

Figure 5-6: Sun shadow analysis of the Premier proposed development. Shadow $45 \%$ transparent black) depicted at summer solstice (6/21/2014) at 12:00 pm EDT.

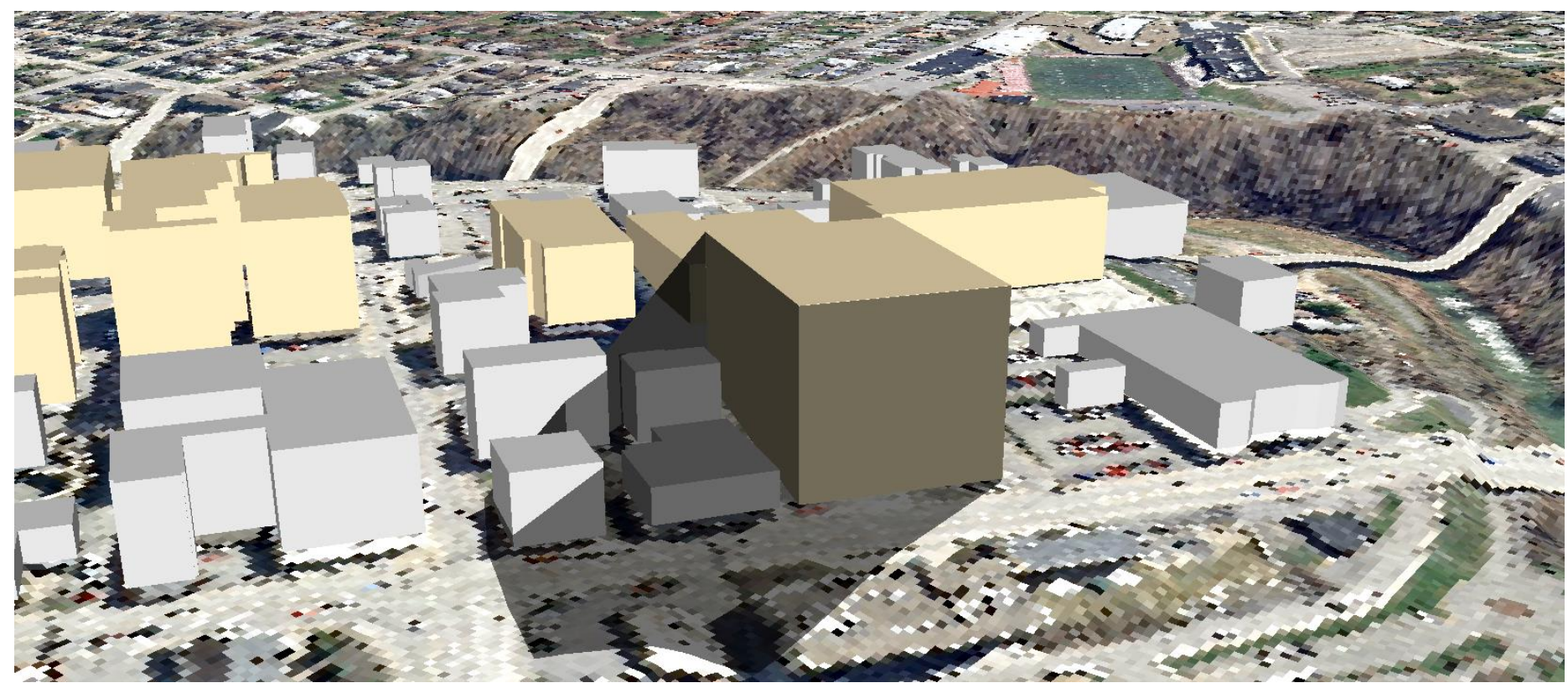

Figure 5-7: Sun shadow analysis of downtown High Street buildings (in beige). Shadow (45\% transparent black) depicted at winter solstice (12/22/2014) at 12:00 pm EST.

The final vignette of the Immersive GeoDesign case study involved identifying intervisibility through line-of-sight studies between structures in the built environment. This visual analysis provides stakeholders with the ability to see where a structure will be visible from 
observer points around town. Since the Intervisibility tool creates an attribute field of binary values indicating "visible" or "not visible," there only needed to be a symbol depicting the sight lines that were constructed to show if the line would be visible (green lines) or obstructed (red lines). Since WVU's campus is included in this analysis, a small subset of procedurallygenerated geosimilar models were combined with the georealistic models of the WVU buildings, providing a more realistic view at an extent suitable for navigation within the CAVE.

The lines-of-sight crisscrossed the Downtown area and enabled visible and non-visible areas and sites to be identified (Figures 5-8 and 5-9). The proposed structure was visible from several of the observation points, especially from locations on the WVU campus. The analysis illustrates that a structure built to maximum height within the Downtown area would be highly throughout that part of Morgantown. This could be a point of contention from the perspective of the several stakeholder communities involved. Also noteworthy is that the different elevations of the observer points, which were placed at different ground elevations and on top of structures, would not be shown in a $2 \mathrm{D}$ representation. To illustrate this point, a $2 \mathrm{D}$ visibility analysis was performed on Downtown Morgantown to provide a more traditional visibility representation (Figure 5-10), using an observer point positioned at a location and elevation on the top of the proposed structure on Don Knotts Boulevard. A glaring difference in the results of the intervisibility and visibility analyses can be seen in which a 2D Downtown Morgantown is essentially devoid of buildings and treated as "bare earth." This comparison of the two analyses provides a powerful example of the capability and need for 3D analysis in GeoDesign. 


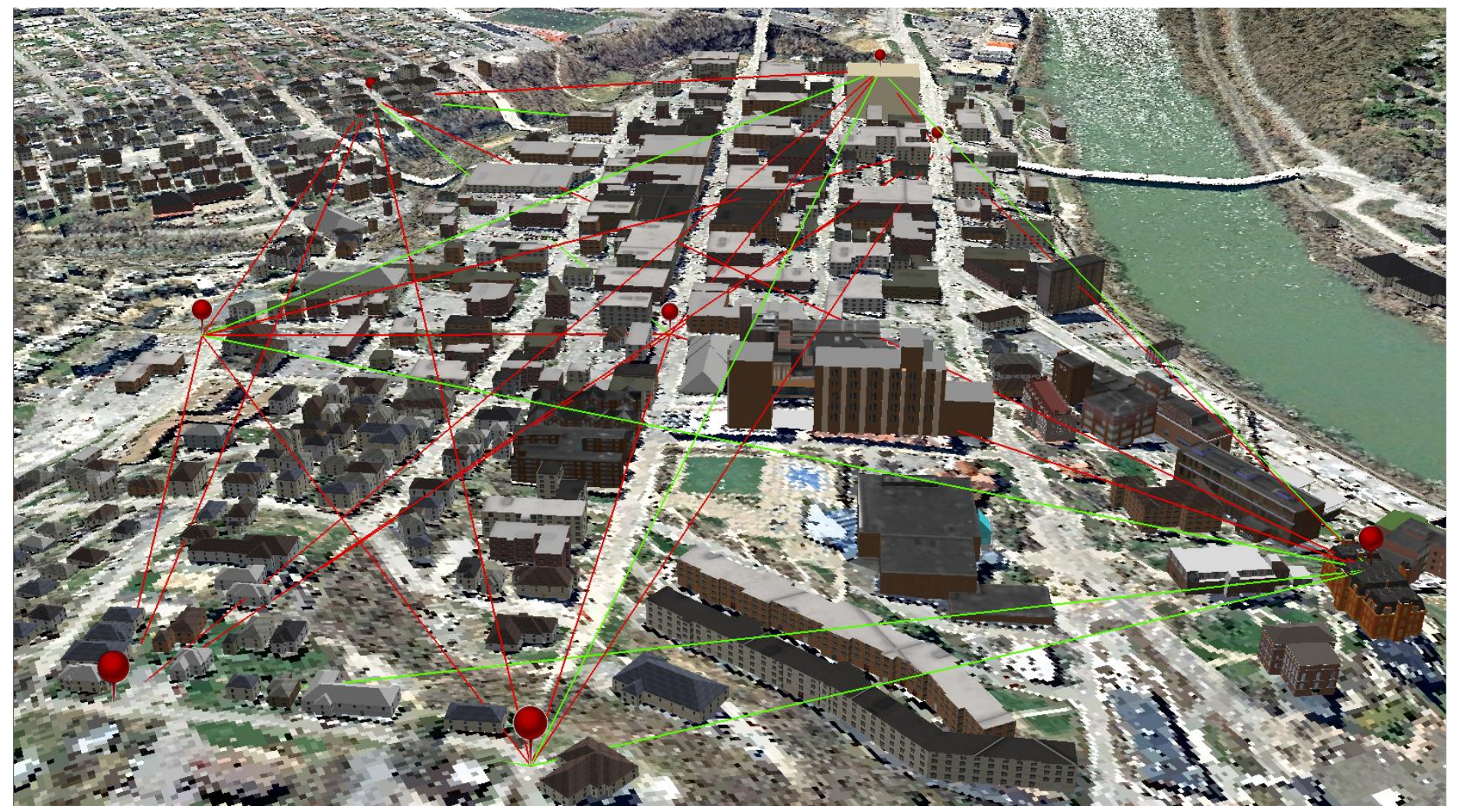

Figure 5-8: Observer points (green flags) and sight lines analyzed with the Intervisibility tool in ArcGIS 3D Analyst toolbox. Lines are symbolized as visible line-of-sight (green), or not visible (red).

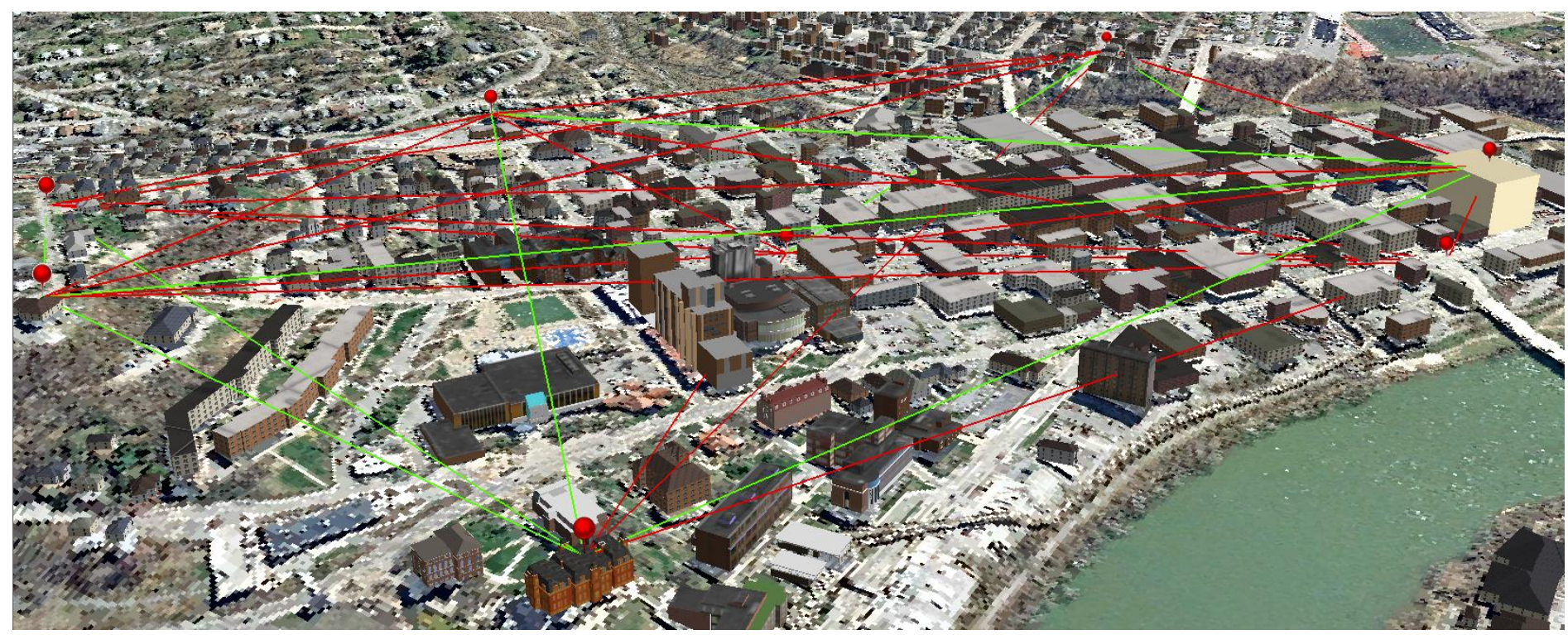

Figure 5-9: A different perspective of the observer points and sight lines analyzed with the Intervisibility tool in ArcGIS 3D Analyst toolbox. The proposed Downtown structure (tan) is shown to be visible from several different observer points. 


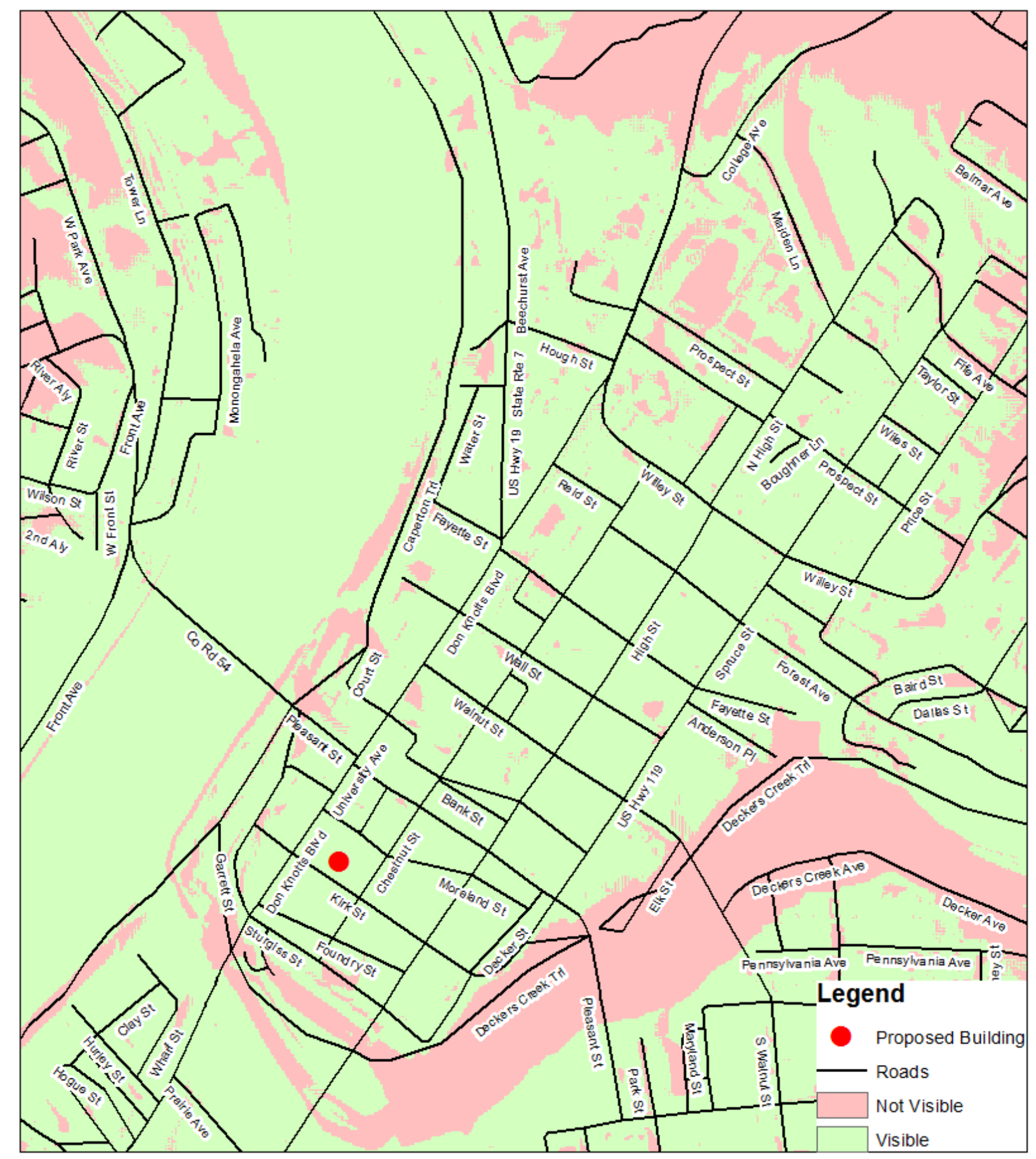

Figure 5-10: A standard 2D visibility analysis map of Downtown Morgantown, WV. Areas declared "Not Visible" and "Visible" based on the observer point at location of the proposed structure (red dot). The map clearly shows areas "Visible" in Downtown Morgantown where in reality, intervening buildings would obstruct the line-of-sight. 


\section{Chapter 6 - Evaluation and Conclusion}

This research produced valuable findings for Immersive GeoDesign but also raised many issues. The several research tasks were pursued in order to address the research goal and research questions concerning the implementation and evaluation of GeoDesign concepts and practices within an immersive CAVE environment using GIS and procedural 3D modeling. GeoDesign concepts and practices were reviewed indicating GeoDesign as a new field that builds on established disciplines, especially geography, planning, GIS, engineering, landscape architecture, and related fields. The research effectively illustrated the ways in which GeoDesign could be advanced through its tight coupling with GIS and 3D modeling. The procedural rule approach of CityEngine provided critical support for GeoDesign through its mass 3D model generation and rendering capabilities exhibited within the case study. The case study also provided a framework for GeoDesign to be implemented within a 3D stereo immersive environment through importing the modeled built environment of Morgantown into WVU's CAVE. The CAVE provided a powerful display platform of the built environment of Morgantown and greatly enhanced visual perception. The geoprocessing utilized within the case study demonstrated how 3D modeling was more than a display tool but enabled 3D geoprocessing to be performed. In this regard, the research succeeded in effectively coupling GeoDesign with GIS and 3D modeling to provide a framework for enabling both representation and analysis of the built environment.

The transition from 2D planning into 3D modeling of the built environment, central to advancing GeoDesign, was completed through the coupling of 3D modeling software packages Trimble SketchUp and ESRI's CityEngine to create a rendered built environment of Morgantown. Trimble SketchUp provided an intuitive interface to construct individual 
georealistic models of focal buildings and landmarks. The level of prior knowledge and experience required to use SketchUp was not steep and would allow users to create 3D models to populate 3D scenes relatively easily. The SketchUp models provide an important addition to the creation of a georealistic built environment, though the downside is that the models existed within a geographical "vacuum" and had to be placed within a CityEngine or ArcScene landscape environment.

CityEngine provided a much faster and efficient method for creating 3D models for a populous rendered built environment, though this was often at the cost of level-of-detail. The learning curve was also considerably greater than that for SketchUp. However, this cost does not diminish the benefit of the final product, which was a geosimilar representation of the built environment of Morgantown, WV. The ability of CityEngine to mass-generate a built environment exemplified a streamlined and very effective approach to GeoDesign when compared to individual models created through software such as SketchUp. While the procedural rule method for generating geosimilar structures represents the real strength of CityEngine, the software's KML import function integrated both SketchUp georealistic models with the geosimilar procedurally-generated buildings. The value of this integration constantly aids GeoDesign and the advancement of Immersive GeoDesign and addresses important issues concerning verisimilitude and level-of-detail.

ArcScene was a required platform to perform the spatial analysis of the built environment and to provide immersion in the CAVE through Conduit. CityEngine and ArcScene have a link for importing scenes through geodatabases, which allows CityEngine to seamlessly export a user's created environment to ArcScene. While the movement between platforms was not a complicated undertaking, the performance of the rendered built environment within ArcScene 
was drastically impaired when compared to its performance within CityEngine because of the lack of caching within ArcScene. The terrain imagery rendered well and provided a valuable backdrop to the urban models. The photo-realistic textures also rendered well for geosimilar and georealistic structures. While the georealistic models were more refined when developed in SketchUp, the geosimilar models were nonetheless more than satisfactory for the tasks pursued. The vertical land use models, because they were only solid colors and not photo-textures, loaded much faster than the photo-realistic versions. However, at the full extent of the rendered built environment, a lag delay did have a marked impact on navigation through the scene.

Several trials using smaller scene extents indicated that a much smaller extent, such as an area consisting of WVU's Downtown Campus, part of Sunnyside and Downtown Morgantown, would allow a much improved frame rate for navigation in the CAVE. The main cause of this issue was the noted lack of a feature cache in ArcScene, which unlike ArcGlobe, can provide immersion through Conduit in WVU's CAVE. Another primary cause of this "frame rate lag" is due to the photo-realistic textures used for the procedurally-generated and SketchUp models. Sacrificing texture resolution for performance would have allowed for an improvement in navigation speed, but would have not met the goal to produce geo-similar buildings.

The rendered built environment was successfully imported into the CAVE and performed well. The performance within the CAVE was correlated to the performance experienced within ArcScene itself, thereby suggesting that the rendering limitations were as a result of the software and not of the hardware. CityEngine visualized the built environment much better in comparison to ArcScene, but along with the inability to render in immersive 3D, the software lacked an appropriate navigation capability for the CAVE that is not planned for development at this time. Panning, zooming, and rotating the view are not intuitive for display control within CityEngine, 
which was designed for a standard mouse and not the Xbox controller used within the CAVE. With that in mind, ArcScene remained the preferred option for exploring the rendered built environment within the CAVE. After the rendered built environment was imported into the CAVE, a few things that could have enhanced the scene, such as background or sky imagery, simulated sunlight, or moving objects, were noticeably absent. While these aspects were not the focus of this research, they do indicate avenues for future research.

The Immersive GeoDesign case study of Morgantown, WV provided an effective platform to showcase the power of GeoDesign coupled with 3D GIS and immersive technologies. The visual analytics and geoprocessing used for understanding the present built environment in terms of 3D land use, parking, light capture and intervisibility cannot be understated as powerful geoprocessing tools for advancing GeoDesign. The vignette of floor-byfloor land use provided a more detailed and accurate depiction of the actual uses for a particular building when compared to a 2D representation. Procedural rules allowed for a streamlined process to thematically map a city based on the zoning codes in the attribute table. However, it must be noted that floor-by-floor visualization requires that structures be designated a land use of "multi-use" or "mixed use" to realize the true value of this $3 \mathrm{D}$ visualization. If a structure is designated only as a single land use, the resulting 3D model will not indicate any unique uses of each floor. Also, while the function of every floor is visualized, it is not at a scale of detail where floor plans or multiple uses on a floor can be depicted at this point in time. This would require more data for each particular floor along with more elaborate procedural rules, and would have exceeded the bounds of the current research.

The procedural rule calculations for parking proved to be useful as a means of extruding an approximation of the space for required parking instead of reporting the number of spaces 
required to the user. The change of the GSF area of a proposed building based on changing the building height correctly provided the corresponding one or two floors of parking required. One strength of CityEngine in this regard is the ability to alter the attributes of a proposed building and for the users to see the changes reflected in real time. This ability is not available in ArcScene, which inhibits implementing alternative stakeholder design requests based upon the results of an impact assessment. A method to combat this deficiency is to export several design scenarios to ArcScene and simply switch the layers within ArcScene's table of contents. Furthermore, the procedural rules cannot report any calculation results concerning volume or floor space to the user since the calculations can only be performed within the script for the purpose of extruding and rendering the model. However, for defined calculations, ArcScene does offer a suitable resource to report values to the user, but this cannot be done from within the immersive environment.

Geoprocessing proved to be a very strong component of the study exemplifying the power of 3D modeling in analyzing the built environment. The light capture analysis vignette provided a powerful visual element to understand light capture issues arising from adjacent taller structures. It should be noted that the Sun Shadow Volume tool in 3D Analyst did produce errors, as mentioned previously. These errors came in the form of the 3D shadow volume being produced as an oblong shape or below the structure being analyzed. These were eliminated by performing the Sun Shadow Volume analysis on smaller groups of buildings or on individual structures. Another finding was that the errors were typically eliminated if the time of day was altered in the tool. Finally, the intervisibility vignette successfully illustrated a strong case for modeling and analysis. Generating sight lines from the observer points to other areas of the town cannot be accurately depicted in $2 \mathrm{D}$ because the analysis did not take account of buildings or 
other structures as obstructions. The results of the Intervisibility analysis in turn were considerably more reflective of reality and an important advance for Immersive GeoDesign.

\section{Demonstration and Evaluation of Immersive GeoDesign}

The purpose of demonstrating this research within WVU's CAVE was to conduct a qualitative assessment and evaluation of the case study over and above meeting the defined tasks as set out originally. Professionals and students with research interests in urban planning and GIS were gathered and the demonstration began with a short presentation of the scope of the research conducted, explaining what 3D modeling can provide over traditional 2D GIS, and illustrating how 2D data is transformed into 3D models. Upon completion of this introduction, the audience entered the CAVE and experienced the rendered 3D models of Morgantown along with the vignettes of the case study. While in the CAVE, a number of questions were posed to the audience to engage them in a discussion of the perceived strengths and weaknesses of 3D Immersive GeoDesign. The questions were as follows: a) What do you perceive as the strengths and weaknesses of 3D Immersive GeoDesign? b) How valuable is it for a user to experience these 3D immersive scenes and to examine real-time design change in the CAVE? c) How valuable do you consider is the ability for a group to observe and discuss these scenes together and in place? d) What value do you consider the four vignettes provided in demonstrating the value of 3D Immersive GeoDesign for planning purposes? e) Do you see value in Immersive 3D GeoDesign? In reality the evaluation turned more into a free flowing discussion at the preference and request of the participants.

Immediately during the demonstration, participants were drawn into a conversation about the built environment, informally discussing the representation, process, evaluation, change, impact and decision models of the Steinitz framework for GeoDesign. Participants were asking 
questions about what exists, identifying areas of improvement, asking about different design scenarios, discussing impacts of design changes, and even possible solutions. Without exception, the group felt very positive about the power of the CAVE to provide a collaborative immersive environment highly suited to planning and design in the urban environment. In particular, the potential for urban planning especially with regard to applications involving vertical land use zoning demarcation, real-time parking needs calculations, sun shadow volume analysis, and intervisibility analysis was noted and applauded. To quote one member of the audience, the Immersive 3D environment coupled with GeoDesign examples reminded him of a dedicated "decision theatre." From the onset of the demonstration the audience was greatly enthused by the rendered built environment and as the various vignettes were displayed and discussed. The ability in CityEngine to change the size and symbology of building models on the fly generated many responses of "wow!" and nonverbal gestures of amazement were noted. One participant speculated that the ability to show different design scenarios on the fly would be immensely powerful. As an important member of the Planning Commission, the participant commented that for "Fifteen years, I have been trying...we have tried to visualize...'well if we do this, what's it going to look like?'...If I had seen this [ability to render models on the fly], I would have [decided differently]." One limitation immediately identified by several participants was the lack of a legend or scale in CityEngine and the requirement for the presenter to explain the symbology of the vertical zoning and parking vignettes. Also, since not every individual land use code for Morgantown was symbolized, many participants felt that it detracted from some of the finer details of land use, such as delineating different densities and type of businesses allowed in the various residential and business land use codes. Participants noticed that the 3D scene could immediately identify "grandfathered" buildings in the planning zone, or 
buildings that did not conform to the zone in which they occurred. Participants were adamant in requesting that the zoning map for Morgantown be applied to the rendered built environment as a point of reference.

The sun shadow volume vignette was commented on by the group as being very powerful and several immediately pointed out the potential light capture issues that setting an arbitrary maximum building height would create for neighboring structures and streets. One participant went beyond simple light capture and noted a potential winter weather hazard combined with a consistent shadow effect could allow icy conditions to remain around the vicinity of the building facing away from the sun. Another participant noted that an "animation of the sun shadow effect throughout the day and not just the solstices and equinoxes" would have been powerful and informative. The intervisibility analyses were identified by one participant as benefitting most from the immersion display because of the ability to navigate and locate the user in the scene and to replicate and experience the actual visibility as well as note the computed intervisibility. One limitation of the intervisibility analysis identified by one participant was that the sight lines obstructed by buildings should have terminated at the point of obstruction rather than continuing to the observer point. The overall results from the presentation and demonstration and were very well received by the participants who indicated that the rendered built environment and vignettes illustrated a strong and very positive case for Immersive GeoDesign.

\section{$\underline{\text { Conclusion }}$}

It is proposed here that based on this research, there is an immense gain to be achieved in developing and using Immersive GeoDesign. The mass-generated models of CityEngine allowed the user to invest less resources into developing the virtual built environment for GeoDesign and to focus those resources into the design aspects. The procedural rule-based 
methodology for prototyping and generating the built environment cannot be understated as it repurposes the resources of GeoDesign beyond understanding what exists in the present to analyzing impacts that might occur in the future. Immersive GeoDesign bridges the gap between planning and technology by providing a collaborative 3D environment within which planners, designers, officials, residents, and other stakeholders can discuss design plans and alternatives. The CAVE provided a valuable platform for collaborative interaction with the rendered built environment beyond what a 2D paper map or 2D computer monitor could provide. The experience of "being there" is something not possible with a 2D representation and navigating and interacting with a rendered built environment in the CAVE allows stakeholders to experience the scene collaboratively in a group setting and creating a more intuitive and creative platform for GeoDesign decision making. The power of 3D GIS cannot be understated when addressing issues such as vertical land use, intervisibility between structures, and building sun shadow impacts. These issues demonstrate a real need for GeoDesign to be studied within the 3D realm as analyses and tasks require that the third dimension be incorporated as part of the analysis. When coupled with Immersive Geography, the visual analytics provided by 3D modeling and analysis in the CAVE creates a valuable platform for expert and non-expert stakeholders alike to make decisions concerning design alternatives and assess possible impacts or benefits. Providing the collaborative environment needed for efficient planning and design decisions makes Immersive GeoDesign a critical area in creating the smart cities of the future. The ability to see the built environment as it is "in reality," and to study proposed changes and design aspects, is a powerful and intuitive experience that is unmatched in the $2 \mathrm{D}$ world. 


\section{Bibliography}

Buchroithner, M. (2012). True 3-D in Cartography: Autostereoscopic and Solid Visualization of Geodata. New York, NY: Springer Press.

Cantrell, B.; Yates, N. (2012). Modeling the Environment: Techniques and Tools for the Illustration of Dynamic Landscapes. Hoboken, NJ: Wiley Press.

Dangermond, J (2010). “GeoDesign and GIS - Designing our Futures.” ESRI, 502-514.

Ervin, S. (May 27, 2011). “A System for GeoDesign.” Keynote Address. 145-154.

Ervin, S. (June 2, 2012). “GeoDesign Futures - Nearly 50 Predictions.” Keynote Address. 22-30.

Flaxman, M. (May 22, 2009). "Fundamentals of GeoDesign.” Keynote Address.

Flaxman, M. (2010). GeoDesign: Fundamentals and Routes Forward. Presentation to the GeoDesign Summit, January 6, 2010, Redlands, CA. Accessible online: http://www.geodesignsummit.com/videos/day-one.html.

Goodchild, M. (2010). “Towards GeoDesign: Repurposing Cartography and GIS?” in Cartographic Perspectives, 66, 7-21.

Harding, C. (2010). "Investigating the Use of 3D Graphics, Haptics (Touch), and Sound for Highway Location Planning" in Computer-Aided Civil and Infrastructure Engineering, $25,20-38$.

Ito, H.; Teh, S.; Nakanishi, H.; Hagawa T. (2005). "Design and implementation of 3D Interface for Digital City" in Electronics and Communications in Japan, 3, 88, 6, 60-68.

Koninger, A. and Bartel, S. (1998). “3D-GIS for Urban Purposes” in GeoInformatica, 2:1, 79-103.

Larice, M. and MacDonald, E. (2013). The Urban Design Reader Second Edition. Abingdon, Oxon: Routledge.

Mach R. and Petschek, P (2007). Visualization of digital terrain and landscape data: a manual. Berlin: Springer.

McGrath, B. (2008). Digital Modelling for Urban Design. Great Britain: Wiley Press.

Morey, D. (2008). "From Vision to Simulated Reality” in Planning, 74, 9, 28-30.

Schaller, J. (May 31, 2012). “Applying 3D Landscape Modeling in GeoDesign” Keynote Address. 235-239. 
Steinitz, C. (2012). A Framework for GeoDesign: Changing Geography by Design. Redlands, CA: ESRI Press

Wheeler, C. (2013). What Could Be. ArcUser, Spring 2013, 58-61.

Wyatt, P. (2003). GIS in Land and Property Management. New York: Spon Press.

Yin, L. (2010). "Integrating 3D Visualization and GIS in Planning Education" in Journal of Geography in Higher Education, 34, 3, 419-438.

Zhang, Y., Zhang, Z., Zhang, J., and Wu, J. (2005). "3D Building Modelling with Digital Map, LiDAR Data and Video Image Sequences" in The Photogrammetric Record, 20, 111, 285-302. Web Sources Cited in Text

ArcGIS Resources - A quick tour of the ArcGIS 3D Analyst extension

http://resources.arcgis.com/en/help/main/10.2/00q8/00q800000003000000.htm

ArcGIS Resources - Intervisibility

http://resources.arcgis.com/en/help/main/10.2/index.html\#//00q9000000nn000000

City of Morgantown Land Use Map

http://www.morgantownwv.gov/wp-content/uploads/official_zoning_map_07-01-2012.pdf

CityEngine Help - CityEngine Overview

http://cehelp.esri.com/help/topic/com.procedural.cityengine.help/html/quickstart/overview.html CityEngine Help - Importing Data Overview

http://cehelp.esri.com/help/topic/com.procedural.cityengine.help/html/manual/import/import_ov erview.html

CityEngine Help - Rule-based Modeling

http://cehelp.esri.com/help/topic/com.procedural.cityengine.help/html/quickstart/usingcga.html

SketchUp-3D Warehouse

https://3dwarehouse.SketchUp.com/?redirect

SketchUp Knowledge Center - Adding detail to your model.

http://help.SketchUp.com/en/article/115430

Solstice \& Equinox Dates 2010-2019

http://wwp.greenwichmeantime.com/longest-day/equinox-solstice-2010-2019.htm 


\section{$\underline{\text { Software \& Data }}$}

ESRI ArcGIS Desktop 10-10.2

ESRI CityEngine 2012.1

Mechdyne Conduit

Monongalia County Commission

Trimble SketchUp 8

All spatial data obtained from West Virginia GIS Technical Center (WVGISTC), 2013. 